\title{
Comentarios a la "Sociología" de Mariano H. Cornejo
}

Por José MEjÍ́a VALERA

\section{(Conclusión)}

\section{LA SOCIOLOGIA GENERAL}

En 1908, apareció, publicado en Madrid, el primer tomo de su obra fundamental, titulada "Sociología General", y dos años más tarde, en 1910, se puso en circulación el segundo y último tomo de la misma.

Este libro marca un nuevo período en la formación doctrinaria de Mariano $\mathrm{H}$. Cornejo, indudablemente mucho mejor documentado y de gran valor didáctico. Como veremos en el comentario posterior, Cornejo tuvo especial cuidado en la estructuración de su sistema para valerse de todas las direcciones que habían informado a lon Sociología hasta entonces, vinculando al fenómeno social no solamente con sus diversas modalidades en sí, sino también con los fenómenos no sociales. La lectura de su obra nos pone de manifiesto el panorama doctrinario de to da una época, habiimente tratado y muy inteligentemente ordenado.

Es sin duda este ordenamiento de las doctrinas el mayor mérito de Cornejo, si bien puede inculpársele de cierta preferencia por la Sociología francesa y por su estilo. Pero, su visión amplia, la crítica a la uni lateralidad de las distintas teorías, su reacción contra el dogmatismo, y el sicretismo de su sistema, hacen de Cornejo un sociológo de indudas ble valer y lo colocan como uno de los estudiosos que preconizaron la falacia del factor predominante en la investigación de la sociedad y de sus fenómenos.

El primer tomo consta de doce capítulos, en que trata de la teoria de la evolución, los primeros hombres, la adaptación y la solidaridad, Ia synergia social y la organización de los grupos, la sociedad y el progreso, los factores sociales, los factores externos, la raza, la herencia, 
Ia población, instrucción y educación, la división del trabajo, y la guerra.

El segudo tomo está dividido en siete capítulos, que se ocupan del lenguaje; mito y religión; el arte; la costumbre, derecho y moral; matrimonio y familia; el Estado; y la ciencia.

Las siguientes páginas contienen un comentario a su sistema de sociología, notable por las razones antes mencionadas, y de gran interés en cuanto a la formación cultural de nuestro medio universitario se refiere.

\section{I.- La filosofía positiva y la teoría de la evolución.}

La primera característica de la Sociolcgía de Mariano H. Cornejo, es, sin aucla alguna, su adhesión a la filosofía positiva iniciada en Francia por Augusto Comte, a mediados del siglo XIX.

Durante los años en que Cornejo preparó el tomo primero de su obra fundamental, imperaba en la América hispana y aún en la sajona, la idea positiva de Comte aplicada a la Sociología. En los Estados Uniclos, Lester F. Ward acababa de publicar, en 1823, su Dinamic Sociology y, más recientemente, en 1895, The Psichic Factors of Civilization, obras que afirmaban les postulados del positivismo, no solamente en cuanto a su método, sino, lo que es más notable, a su ideal, la constitución de la sociocrácia. En Lima Comte se habia convertido en el nuevo Bacon de las disciplinas especulativas.

Cornejo, pues, bebio de este ambiente positivo, asimilando sus principios, dirección que determinó su especial posición en el campo de la Scciología.

La filosofía de los fenómenos sociales esta enlazada - afirma- con la filosofaí de los fenómenos universales, y según el concepto que se tenga del universo; teológico, metafísico o positivo, será la idea que se posea de la Sociología: providencial del destino de los pueblos, sistemas trascendentales de filosofía de la historia y determinismo de las leyes que rigen la dinámica social. (1).

Dos temas centrales juegan en las ideas de Cornejo al adherirse a la doctrina positiva de la Sociología : a) el origen y naturaleza de las cosas no puede ser conocido científicamente, y b) todas las nociones que se refieren a la sociedad tienen que ser esencialmente relativas. Ámbos son, en esencia, el resumen del positivismo de Comte y del

(1) Cornejo, Sociología, etc., p. 37. 
neo-positivismo de Poincaré. Cornejo deduce de esto, que la conclusión filosófica más importante a que había llegado el siglo XIX, es que el análisis científico debía limitarse a estudiar el desenvolvimiento de los fenómenos y sus relaciones, y renunciar a toda clase de explicación sobre la naturaleza, origen y fin de las cosas, imposible dentro del criterio de la experiencia y de la lógica y que, por último, todas las hipótesis sobre el origen del universo son capitulos que para la inteligencia, reducida a sus propias fuerzas, resultan inconcebibles, y fuera del análisis de la ciencia. Como el fin, o sea el destino trascendental del universo, caso de existir, es consecuencia de su origen, es evidente que, desconocido éste, tampoco aquel es susceptible de conocimiento científico. (2).

Por lo tanto, las nociones referentes a la sociedad tienen que ser relativas, puesto que reducidos a lo único cognoscible : las propiedades sensibles de los objetos, cualquier labor intelectual sólo nos muestra la parte de la realidad que se deja encerrar en el marco de la "sucesión" y la "coexistencia". (3) La ciencia, en estas condiciones, está limitada a registrar, en fórmulas generales, la coexistencia y sucesión, y las semejanzas y diferencias de las ideas que corresponden a las cosas. (4) Además, como toda ciencia tiene como fin la sistematización y clasificación, la mejor teoría es aquella que explica todos los fenómenos, porque facilita la clasificación y extiende el campo de la experiencia. (5).

Por último, la "ciencia social positiva", cuyo fin es estudiar científicamente la sociedad, no gha de buscar btra cosa que las relaciones de los fenómenos sociales, procurando fijar leyes de coexistencia y suce. sión. (6).

La filosofía positiva, desde el punto de vista histórico, tuvo su antecedente en el desarrollo que, durante los siglos XVII y XVIII, adquirieron los procedimientos de investigación natural. $\bar{A}$ partir de Bacon $\mathrm{Y}$ Newton, el método experimental fue cada vez compenetrándose más con la ciencia, hasta que llegó a considerarse que la única forma de llegar al conocimiento de la verdad era mediante la observación, experimentación y comprobación.

(2) Ibid., p. $38,41$.

(3) Ibid., p. 44.

(4) Ibid., p. 46 .

(5) Ibid., p. 47

(6) Ibid., p. 47. 
Ya desde la época de Manuel Kant, la filosofía también recibió la influencia de la obra de los naturalistas, pues aquel afirmó que sólo podíamos llegar al conocimiento de los fenómenos, mas no de la esencia de las cosas, o noumenos, rechazando prácticamente toda especulación metafísica. Augusto Comte coordinó estas ideas con las de Turgot, Condorcet y Saint Simón para producir su filosofía positiva y negar todo conocimiento metafísico, y asirse, firme y únicamente, al conocimiento propio de las ciencias naturales.

Ei positivismo significa un llamado a la realidad, a los hechos que pueden ser observados por los sentidos. Pero para llegar a esa realidad sólo nos ofrece un camino : el método experimental. Ahora bien, la Sociología, como una derivación de la Biología, también podría estudiarse aplicando dicho método, como si los fenómenos sociales tuvieran la misma naiuraleza de los físicos y biológicos. Comte consideró que en ellos también podía establecerse leyes de coexistencia y suce. sión, esto es, descubrir las relaciones entre los fenómenos sociales pe. ro no pasar de ellas, vale decir, no salir fuera del ámbito de la realidad. La ley de los tres estados es un claro ejemplo de esta tendencia del positivismo.

Aún cuando Augusto Comte no aplicó la experimentación para construir su Sociología, sus continuadores, en especial John Stuart Mill, se dedicaron a especular respecto $a$ - las reglas del método y a sus resultados prócticos. Un primer problema, pues, que nos plantea el pos sitivismo, es la posibilidad de usar el método experimental en el conocimiento de los fenómenos sociales.

Pronto se levantó, en el campo de la filosofía, una corriente contraria al positivismo, encabezada por Guillermo Dilthey, en Alemania, anunciando que no podía tratarse los fenómenos del espíritu con la misma medida que los de la naturaleza. El mundo espiritual fue opuesto al mundo de la naturaleza no sólo en su esencia sino también en cuanto a la forma como debía interpretarse y conocerse.

Fué sobre el análisis de las ideas de Kant que Dilthey estructuró la fundamentación de las ciencias del espíritu. Consideró que la idea criticista hacía del tiempo, y por lo tanto de la vida misma, un mero fenómeno que no correspondía a su realidad interna, y que en el curso de la vida, o sea en el crecimiento desde el pasado y en la proyección hacia el futuro, radican las realidades que constituyen el nexo efectivo $y$ el valor de nuestra vida.

Si tras ella, que transcurre entre el pasado, el presente y el futuro, hubiera algo atemporal, entonces constituiría un antecedente de la vida, sería como una condición de su curso en toda su conexión, aquello 
que precisamente no vivimos, y por lo tanto, un reino de sombras. Esta proposición es fundamental en la filosofía de Wilhelm Dilthey pues. to que lo aparta por completo de la vieja oposición realista- idealista, para colocarlo en el centro de nuestra propia existencia, en nuestra vida y experiencia, es decir, en nuestro ser, dentro del cual se dan, no solamente la realidad del yo, sino, sobre todo, la naturaleza misma.

La idea fundamental de Dilthey radica en la oposición entre el mundo exterior, o mundo de lo dado en la percepción exterior a través de los sentidos, y el mundo interior que se nos ofrece en la vivencia. La representación del mundo exterior proviene de nuestros sentidos; mediante ellos, nos percatamos de los objetos que componen ese mundo y por lo tanto también nos colocamos en él. Pero si advertimos que dentro de nuestro ser íntimo hay experiencias directas y no consiruídas, en las que el sujeto y objeto coinciden perfectamente, y ésta está presente en nosotros, o sea se produce una actualidad vivida, es decir una vivencia, entonces podemos comprender lo infinitivo de ese otro mundo opuesto al exterior. La vivencia intema nos proporciona un conocimiento, mucho más directo, de la enorme amplitud de nuestra interioridad y, sobre todo, de la objetivación de ella en los bienes culturales del mundo espiritual.

Así la vivencia le sirva de fundamento para demostrar la realidad objetiva de la experiencia interna, la verificación de la existencia de un mundo exterior $y$, por último, que en ese mundo exterior se presentan hechos y seres espirituales en virtud de un- proceso de transferencia de nuestra interioridad.

La diferencia de las ciencias del espiritu con las ciencias de la naturaleza, se encuentra, para Dilthey, en un distinto punto de partida. Mientras las segundas marchan de fuera hacia adentro y pueden avanzar con paso firme en su terreno propio, en cambio se detienen de inmediato cuando ya no es posible aplicar la conexión causal natural a los cambios psíquicos, puesto que los hechos del espíritu constituyen el límite supremo de los hechos de la naturaleza, a la vez que los hechos de la naturaleza constituyen las condiciones ínfimas de la vida espiritiual. (7).

Dilthey se esfuerza en distinguir los conceptos opuestos de lo psíquico y lo físico, para lo cual profundiza en el análisis filosófico con magistral hondura. Llamamos lo psíquico, dice, a la conexión de vivencias que se mantienen a lo largo de toda nuestra vida, y abarca nues-

(7) Dilthey, Introducción, etc., p. 23. 
tras representaciones, fijaciones de valor y de fines, y consiste en la union de estos miembros. Los objetos físicos, en cambio, son aquello que se coloca debajo de las impresiones que se presentan en la vivencia y permite, mediante su "posición". "construir" esas impresiones. Ambos conceptos pueden ser utilizados siempre que tengamos conciencia de que han sido abstraídos del hecho hombre. (8).

Con estos dos puntales perfectamente definidos, Dilthey asume la tarea de diferenciar las ciencias del espíritu de las ciencias de la naturaleza, considerando que la distinción no se encuentra únicamente en que las primeras se refieren al hombre y a la realidad histórico social. puesto que la fisiologia también está dirigida hacia él; sino, sobre to. do, en que en las ciencias del espíritu actúa una tendencia que se funda en la cosa misma, que está orientada hacia la "comprensión" puesto que utiliza toda manifestación de vida para capturar lo interior que lo Froduce, aquello que $\in s$ inaccesible a los sentidos, algo que es únicamente vivible, algo de donde proceden los hechcs exteriores que les es inmanente y sobre lo que repercuten; y esta tendencia se funda en la vida misma, porque en estas cosas que se pueden vivir se halla comprendido todo valor de la vida, en torno a ellas gira todo el alborto ex. terior de la historia y aquí se nos presentan fines de los que la naturaleza nada sabe. En la vida es donde únicamente aparece el "sentido". el "valor" y el "fin". (9) Esta tendencia de las ciencias del espíritu se manifiesta, pues, en ese retroceso del curso sensible exterior del acontecer humano a algo que no cae bajo los sentidos, para captar y comprender aquello que se manifiesta en el curso exterior. Sólo ahí donde existe comprensión se da esta relacion de lolexterno con lo interno, como sólo ahí donde hay conocimiento natural se da la relación de los fenómenos con aquello mediante lo cual son "construídos".

Para Dilthey, sin embargo, no es psicológico el estudio de este aspecto interno del curso de la vida, puesto que el Derecho y la Estética, por ejemplo, constituyen la expresión de un sistema de fines y la conexión significativa de su expresión. Finalismo y significación, pues, son los dos grandes objetivos de las ciencias del espíritu en el acto de "comprender", a diferencia de las ciencias de la naturaleza que con. ciben un "objeto físico" en el "conocer". (10).

Con esta introducción ya es fácil ingrescir a la separación de las ciencias naturales de las espirituales, mediante características ciertas.

(8) Dilthey, El mundo histórico, p. 10.

(9) Ibid., p. 102.

(10) Ibid., p. 105. 
Lo humano captado por la percepción y el conocimiento, sería para nosotros un hecho físico $\mathrm{y}$, en este aspecto, únicamente accesible al conocimiento natural, pero se convierte en objeto de las ciencias del espiritu en la medida en que se "viven" estados humanos, en la medida en que se expresan en "manifestaciones de vida" y en la medida en que esas expresiones son "comprendidas". Así pues, para Dilthey la conexión de vivencia, expresión y comprensión constituyen el método propio por el que se nos da lo humano como objeto de las ciencias del espíritu. (11) Sobre la base de estos fundamentales conceptos, desarrolla el filósofo alemán su magistral teoría de las ciencias del espíritu.

La ncturaleza - dice el pensador - forma parte de la Historia únicamente en aquello que actúan sobre nosotros y que nosotros podemos actuar sobre ella. El reino propio de la Historia es también exterior, pero sin embargo, los sonidos que componen una pieza musical, el lienzo sobre el que se pinta un cuadro, la audiencia en que se pronuncia una sentencia, la prisión en que se cumple una condena, de la naturaleza reciben tan sólo su material $y$, por el contrario, toda operación científico-espiritual que se realice con estos hechos exteriores tiene que ver únicamente con el "sentido y el significádo" que obran por la acción del espiritu que está al servicio de la "comprensión" que capta ese sentido, ese significado. (12).

Este comprender no sólo designa la actitud metódica propiciada por Dilthey, puesto que entre la ciencia del espíritu y la ciencia de la naturaleza no se trata únicamente de una diferencia en la posición del sujeto con respecto al objeto, en un tipo de actitud, en un método, sino que el método comprensivo estáfundado realmenteen el hecho que lo exterior, en que consiste su objeto, se diferencia del objeto de la ciencia natural de un modo absoluto. El espíritu se ha objetivado, se ha formado fines, se ha realizado valores, y precisamente este algo espiritual, incorporado al objeto, es lo que capta la comprensión. Entre el objeto y yo, existe una relación de vida.

La Sociología, como ciencia que tiene su campo de investigación en la realidad histórico social, no escapa a esta fundamentación dada por Dilthey para las ciencias del espíritu. Si bien es cierto que el filósofo se preocupó especialmente por la estructuración del mundo histórico como expresión prístina del hacer y padecer del hombre en su mundo, en cambio formuló todo un sistema sociológico al intentar la ordenación sistemática de la realidad social. Para Dilthey la Sociología del

(11) Ibid., p. 107.

(12) Ibid., p. 140. 
estilo que propiciaron Comte, Spencer, Shaeffle y Lilienfeld, que hizo de la ciencia social una enciclopedia de los conocimientos que hasta entonces se habían reunido sobre el hombre y su cultura, carecia por completo de sentido científico, no constituía verdadera ciencia y su tarea resultaba así insoluble. (13).

Sin embargo, por entonces en Alemania se gestaba un poderoso movimiento en cuanto a la nueva ciencia se refiere que, al ser advertido por Dilthey, lo hizo retractarse de sus anteriores afirmaciones, las cuales, dijo entonces, se habían referido a disciplinas que no ofrecían una teoría de las formas que adopta la vida psíquica bajo las condiciones de las relaciones sociales de los individuos. Y frente a la obra de Simmel manifiesta que ya en su Introducción había caracterizado la organización exterior de la sociedad como un campo especial en el que, desde un punto de vista psicológico, operan relaciones de señorío y dependencia y relaciones de comunidad. "Mi concepción se diferencia de la de Simmel, agrega, en primer lugar porque yo no puedo reducir esas fuerzas unitivas sencillamente a los "factores" psiquicos indicados, sino considero como igualmente importantes la conexión natural que supone la comunidad de sangre, de familia y raza como, por otra parte, la convivencia impuesta por el sentimiento común. Mi repudiación a la Sociología no puede, por lo tanto, referirse a una disciplina semejante, sino que afecta $\alpha$ una ciencía que pretendía abarcar en una disciplina única todo aquello que tiene su escenario en la sociedad humana. (14).

La fundamentación delas ciencias delespiritu, entonces, es también una fundamentgción de la Sociología como ciencia de la sociedad, de la realidad histórico social, de la infinita gama de las preocupaciones teeológicas del hombre y de la organización exterior de la sociedad.

Si la historia como ciencia no puede captarse sino dentro de los marcos de la "comprensión", con mucha mayor razón el tema propio de la Sociología necesita de este método, toda vez que en el ancho panorama de las manifestaciones de los hombres y de sus instituciones, es necesario encontrar no una simple sucesión y coexistencia en el tiempo y en el espacio, sino el sentido final de las organizaciones humanas. No interesa su fijación cronológica o geográfica, sino su interpretación en el amplio mundo de los fines. La simple descriptiva de costumbres primitivas no nos llevaría más allá de un conocimiento casuístico, de la fijación de un hecho físico al estilo de las ciencias naturales, pero si

(13) Dilthey, Introducción, p. 106.

(14) Ibid., p. 454. 
logramos captar el finalismo de las ceremonias, la teleología del derecho que encuentra su existencia exterior en el aparato jurídico, o el sentido y significado de los partidos políticos, entonces habremos comprendido a la sociedad misma, a la objetivación del espíritu, a la actividad interna del hombre que se encarna en el mundo de lo físico y lo utiliza comc su medio de expresión simbólica. Penetrar en el simbolismo del hombre, entender su tiempo, su espacio y su cultura dentro de los límites de su propia espiritualidad, es conocer el verdadero campo de lo social que se da en nuestra propia conciencia. Vivimos una guerra y por lo tanto podemos conocerla e interpretarla, a diferencia de un hecho físico que solamente podemos construirlo.

Mucho se ha discutido sobre la orientación que debía informar el desarrollo de las investigaciones en Sociología, y largo también ha sido el camino recorrido. A partir de Comte y Dilthey, dos grandes tendencias se disputaron el dominio de la ciencia de la sociedad en cuarsto a método y finalidades; la Sociología Pura y la Sociología Empírica.

La primera, tratando de comprender los fenómenos sociales se extravió por los caminos de la metafísica, llegando al extremo combatido por el positivismo. Es indudable que mucho se avanzó por esta ruta, pero no precisamente porque el método fuera acertado $\mathrm{y}$ abarcara la totalidad de los fenómenos, sino por la genial intuición de las personas dedicadas a esas elucubraciones. La segunda, reaccionó contra la simple especulación filosófica sin caer en los extremos del positivismo, para apoyarse en la realidad tangible yemensurables sin desconocer la validez de la comprensión y la naturaleza espiritual de la conducta social. Mientras la Sociología especulativa se dedicó "a discutir la teoría de los grupos naturales, tales como la horda, tribu, familia, nación, agrupamiento raciales, etc., en cambio la Sociología empírica comenzó a investigar la realidad contemporánea desde sus más pequeñas manifestaciones, y a medirla con métodos especiales que han reunido un inmenso material y originado una nueva disciplina; la Sociometría.

El problema actual de la Sociología se resume en considerar si de. be subsistir únicamente la Sociología especulativa o darse mayor importancia a la Sociometría o Sociología empirica.

La sociología especulativa, fundada sobre bases filosóficas, no puede desaparecer del todo en la orientación de las investigaciones, porque ella contiene los principios de estructuración y comprensión que son necesarios para poner orden en la multitud de pequeñas monografías y medicipnes de la realidad social. La sistematización de los datos proporcionados por la sociometría debe tener una base doctrinaria que contemple la multitud de problemas que se presentan en la organi- 
zación social y en su estructura. Nada se avanzaría con reproducir la verdad social en el papel, mediante un método estadisticio, por ejemplo, si ella no es interpretada y comprendida en todo su verdadero sentido, estableciendo secuencias y funciones.

Es evidente que la pureza de la sociolcgía no puede tomarse en el sentido que tuvo durante la segunda mitad del siglo XIX, pues la simple especulación metafísica no nos explica la realidad social. Es preciso que exista una sistematización de los conocimientos y que estos se extraigan mediante procedimientos adecuados y no con la ayuda de la sóla intuición u observación, muchas veces parcial e incompleta.

Hay quienes han afirmado la posibilidad $y$ hasta la necesidad de la investigación, pero manteniéndola siempre separada de la sociología, la misma que asumiría, en esta manera, una marcada tendencia silosófica. Ha sido en los países de habla inglesa donde pacientemente se ha desarrollado la técnica de la investigación social y opuesto su realidad a la subjetividad de la sociología especulativa. Pero este divorcio entre ambas ramas de la misma ciencia no puede lograr otra cosa que anular el esfuerzo de todos y cada uno de los trabajos que se hagan en uno $u$ otro campo. Es necesario, pues, encontrar el tránsito entre los momentos de la investigación y la teoría, que no puede estar sino en el problema del método. La sociometría es, fundamentalmente, aplicación del método de la investigación social, mientras la sociología pura debe ser la sistematización de los datos proporcionados por dicha investigación. 1 blloteca de Letras

Es notable el desarrollo deila sociografía $€ n$, los Estados Unidos, Inglaterra, Francia y Brasil. Durante casi todo el siglo XIX, la mayor parte de las investigaciones en sociología se fundaban en observaciones generales y en lógica especulativa, pero alrededor de 1920, los métodos para medir los procedimientos sociales han sido considerablemente perfeccionados. En la actualidad se mide la opinión pública, las tendencias sociales, las actitudes con respecto a algún problema público; se llevan índices de mortalidad, morbilidad, nacimientos, defunciones. migraciones, matrimonios, divorcios; se pronostica los cambios de afiliaciones a los partidos políticos, el aumento y descenso de las ideologías, etc., y por este camino, la sociología va adquiriendo verdadera categoría de ciencia, pues sus conclusiones pueden apoyarse ya en hechos tangibles, recogidos mediante procedimientos que merecen fe, $y$ por un personal técnicamente entrenado e instruído.

La sociometría y la sociología pura, se aúnan en el momento de la sistematización, de suerte que la una carece de significación sin la otra, $y$ ésta de objeto sin la primera. 
Lejos ha quedado ahora la idea de Comte de aplicar a la Sociología los métodos de las ciencias naturales. Bien es verdad que en los Estados Unidos se esiá desarrollando una tendencia para aplicar el método experimental en las investigaciones sociales, controlando las variables o igualando las condiciones que rodean la aparición de ciertos fenómenos, pero hasta la fecha sólo ha podido llevarse a cabo en pequeñas formas de asociación, como las reacciones al trabajo, en niños de dos a tres años, o la adaptación grupal en jóvenes universitarios.

Mariano $\mathrm{H}$. Cornejo nada nos dice respecto a los métodos propios de la Sociología, salvo que los hechos de la sociedad tienen la misma naturaleza que los físicos, químicos y biológicos. Esto, naturalmente, lo llevó hasta los extremos del mecanicismo, doctrina que representa el aspecto nefasto del positivismo. Si el llamado a los hechos, a la realidad, ha tenido acogida dentro de la doctrina sociológica, en cambio, la hipótesis que los fenómenos sociales gozan de igual naturaleza que los físicos y pueden aplicárseles sus leyes, ha sido próntamente repudiado por los tratadistas contemporáneos.

El mecanicismo de Cornejo se fundó, casi esencialmente, en la obra de Herbert Spencer. Considera que la hipótesis mecánica del universo es la única que se presta a un conocimiento científico (15) conforme a lo demostrado en "Los Primeros Principios", cuyos postulados tendrían aplicación a los órdenes no solamente cósmico sino también orgánico y social. (16) Como la vida es inconcebible sin el medio, y como no hay solución de continuidad entre el universo y el hombre, es claro que los fenómenos humanos ofrecen relaciones también persistentes, cuyas condiciones pueden ser conocidas. (17) La vide no "puede concebirse sino como una serie de movimientos complejos, desde los moleculares de la asimilación, hasta los visibles de los órganos. El proceso vital se desenvuelve en un proceso de acumulación y gasto de energía, llamado anabolismo y metabolismo. (18).

Estas transformaciones -continúa el autor-alcanzan también a la vida psíquica, que se nos presenta como un fenómeno cuyos antecedentes, pasando por las formas biológicas y químicas, se resuelven en fenómenos mecónicos. Las impresiones de los sentidos producen sensaciones diversas, que lógicamente deben considerarse también como transformaciones de las fuerzas que las originan, puesto que la misma

(15) Cornejo, Sociología, etc., p. 48.

(16) Ibid., p. 55.

(17) Ibid., p. 56.

(18) Ibid., p. 60. 
equivalencia que hay entre las fuerzas físicas y las sensaciones, exis. ten entre éstas y las acciones fisiológicas, que son su consecuencia, como sucede con las contracciones musculares que avivan los latidos del corazón, aceleran la respiración o excitan los órganos secretores. (19) Con los pensamientos y sentimientos existe la misma relación, aunque más difícil de apreciar. (20) Si la transformación de las fuerzas - sigue Cornejo- abraza en su radio de acción las fuerzas psíquicas, necesariamente tiene que comprender las fuerzas sociales. Todo cuanto en la sociedad acontece no es sino la consecuencia o de factores físicos, orgánicos o psiquicos, de manera que el fenómeno social es otra transformación de la fuerza cuyo proceso está determinado siempre por causas y condiciones, algunas de las cuales pueden ser percibidas cualitativa y cuantitativamente. (21).

Las fuerzas sociales - propone el sociológo- pueden considerarse en este sentido como una trasformación del calor solar, una consecuencia de la gravedad que concentra continuamente la materia que forma el sol. La vida de la sociedad depende de los productos minerales, vegetcles y. animales que no son sino transformaciones de la energía acumulada por los rayos solares en el sueloo y subsuelo del planeta. (22) Los factores humanos de la sociedad, la raza y la población, dependen del medio físico; los fenómenos económicos, tan íntimamente ligados a las fuerzas del medio, tienen una acción decisiva sobre la vida social, $y$ en suma, este fenómeno de transformación de unos modos de energía en otros, no es sino una consecuencia del principio fundamental de la persistencia de Ialenergía (23): SO"

El principio de la dirección hacia la mínima resistencia crece en importancia para Cornejo, cuando se aplica a la vida orgánica y la sociedad, porque nos presenta los fenómenos orgánicos y sociales co. mo fenómenos de equilibrio. En general todos los fenómenos orgánicos, sin excluír los psíquicos, estan determinados por una disminución de resistencia, y todo el estudio de İa Sociología se reduce a descubrimos las diferencias potenciales de las energías sociales. (24).

La población crece, los grupos étnicos se acumulan ahí donde son menores las fuerzas antagónicas. La inteligencia social comienza
(19) Ibid,, p. 61.
(20) Ibid., p. 62.
(21) Ibid., p. 64.
(22) Ibid., p. 64
(23) Ibid., p. 65.
(24) Ibid., p. 69. 
por la dominación de un grupo sobre otro y esa acción está determinado directamente por la menor resistencia. (25) Entre dos formas políticas, entre dos sistemas religiosos, se arraiga aquel que, dadas las circunstancias, ofrece menor dificultad a la inteligencia. Considera que las repeticiones rítmicas también se manifiestan en los fenómenos sociales, y gracias a ellas existe la Sociología, y que la no repetición del movimiento complejo del agregado hacia formas superiores de evolución, da lugar a la existencia de la Historia. Consecuencia del ritmo social, o repetición de los movimientos elementales en que se descomponen los fenómenos complejos, son las leyes sociales. (26).

La aplicación de los principios mecónicos a la hipótesis de la sociedad y su desarrollo, ha sido del todo desafortunada en la Sociología. La simple analogía, que en la mayor parte de los casos puede reducirse 'a sólo una metáfora o giro del lenguaje, no ha podido comprobarse en las investigaciones fácticas. No hay ningún estudio serio que haya demostrado que los fenómenos sociales sean producto directo de fuerzas físicas debidamente transformadas. Por otra parte, ya Dilthey ha profundizado la naturaleza de los actos voluntarios e intencionales de las personas, base de los hechos sociales, y nos ha abierto un panorama completamente distinto y altamente promisor.

La intencionalidad de la conducta humana y su sentido y signifi cación, no pueden ser explicados por la teoría mecanicista. Sorokin ha criticado sus exageraciones, tafimando que ella no puede aportar razón respecto a los actos de los in dividuos y la variedad inmensa de sus acciones, con la simple aplicación de los principios de la mecánica física, la inercia, la gravitación o los fundamentos de la palanca de primero o segundo grados. ¿Nos ayudaría - pregunta- a comprender por qué " $A$ " se hace ermitaño, " $B$ " se casa, " $C$ " muere en una batalla, " $D$ " escribe un poema, etc.?, ¿Arrojarían alguna luz estos principios so. bre los fenómenos religiosos, políticos, estéticos y otros análogos? ¿Pueden explicar por qué la histria de un pueblo se ha desarrollado en un sentido y la de otro ha seguido un camino completamente diverso? (27).

El mecanicismo llevó a Cornejo a participar de todas las falacias propias de la escuela, si bien es verdad que su influencia era poderosa durante la época de formación doctrinaria del sociológo peruano.

(25) Ibid., p. 70 .

(26) Ibid., p. 74.

(27) Sorokin, Teorías, etc., p. 37. 
Pero el mecanicismo también condujo a Cornejo hacia la teoría de la evolución, que, asimismo es cierto, llenó por completo casi todas las obras de Sociología de la segunda mitad del siglo XIX.

Cornejo, desde el primer momento, hizo suyas las especulaciones que encontró en "Los primeros principios" y no.vaciló en reproducir, en síntesis clara y sencilla, los postulados que Spericer había utilizado para el desarrollo y exposición de su teoría evolutiva. Después de asinilar la hipótesis mecánica'del universo y calificcrla como la única que ofrece el dato fundamental de la cantidad, y por lo tanto accesible con perfecta certeza a la inteligencia, manifiesta que tal hipótesis ha permitido crear la teoría de la evolución, tan fecuda para la ciencia en general, y en especial para el análisis de los fenómenos sociales; y que su importancia radica en prescindir de la naturaleza de las cosas, limitándose a encerrar en una síntesis general sus relaciones. (28).

Desde este momento Cornejo vinculó el positivismo con la evolución, formando una continuidad doctrinaria que, indudablemente, constituye su mayor mérito.

Sobre la base de la teoría de Spencer, Cornejo asimiló todas las tendencias de la escuela evolutiva con magistral talento, desterrando de cada una lo que creía exagerado y modificando en parte determinadas hipótesis con el objeto que, dentro de su sistemática, no ofrecieron mayores implicanciais $\rho$ contradicciones. Las ideas de Comte, Spencer, Gumplowicz, Lerter Ward, Giddigns, Bachoffen, Taylor, Morgan, elc., pueden encontrarse confundidas $y$ reordenadas dentro de un nuevo principio director, cual es el sentido de la integridad del fenómeno siscial.

Comienza explicando la evolución de la vida, desde su nacimiento en los mares tibios, siquiendo en esto el primitivo plan impuesto por Spencer y continuado más tarde por Giddings, su paso por las diferentes etapas geológicas con la consecuente multiplicación de las especies, la aparición del hombre, la formación de las razas $y$, por último, el de. sarrollo paulatino de las actividades culturales. (29).

En este punto se detiene para recibir la influencia de Gumplowicz, al aseguror que la hipótesis poligenista, en cuanto al origen del hombre, proporciona a la Sociología el punto de partida para explicar la multi-

(28) Cornejo, Sociología, etc., p. 48.
(29) Ibid., p. 107. 
plicidad de elementos étnicos que originarían, más tarde, las tribus prehistóricas. (30).

Los estímulos para la evolución orgánica y social son, para Cornejo, siguiendo en esto $\alpha$ Ward y Giddings, el cleseo y sus consecuencias el placer y el dolor. A medida que son más intensos y variados los desecs y sus afectos placenteros y dolorosos, serán más perfectas las formas de equilibrio que alcancen los organimos y las sociedades. Cree Cornejo que a las fuerzas externas de la evolución cósmica, se suman las fuerzas internas simples de la evolución orgánica, las que en la evolución social se transformarían en representanciones psíquicas del interés del todo y de las partes, que se armonizan en la solidaridad, $a$ socióndose a la idea de Durkheim, de quien acusa fuerte influencia, al extremo de interpolar los principios que figuran en "De la división du travail social", con los de la sociología norteamericana.

Expone, luego, que en las necesidades orgánicas de la horda se encuentra el gérmen de todas las instituciones; necesidades que son verdaderas fuerzas llamadas a constituir el proceso social. A partir de aquí la recepción doctrinaria se refiere íntegramente a Lester F. Ward.

Junto con él, cree Cornejo que lo estructura social es el resultado de la actuación combinada de muchas fuerzas que tienden hacia el equilibrio, proceso que importa la "Synergia social".

Por intermedio de Ward llega hasta las fuentes del darwinismo social y acoge con entusiasme la afirmación de Gumplowiez que los conflictos son creadores de fuerzas capaces de modificar l $\alpha$ estructura de la sociedad. La explotación del hombre, de los animales y de las fuerzas naturales, he ahi el camino que habria seguido la humanidad.

La teoría de la evolución saturó todo el pensamiento de Mariano H. Cornejo y le facilitó la estructuración de un sistema fundado en la doctrina positiva, que recomendaba el trato de los fenómenos sociales al igual que los físicos y naturales, completado por la teoría de Spencer, que proclamó la creencia que la evolución orgánica y superorgónica o social no eran sino simples derivaciones de la evolución cósmica, y por consiguiente aplicables a ellas los principios físicos, referentes a la indestructibilidad de la materia y la conservación de la energía; y. por último, adicionado por las tendencias históricas y darwinistas ya antes anotadas.

Pero, ¿las afirmaciones de la teoría de la evolución son enteramente válidas y favorecieron el desarrollo de los estudios sociales? Antes

(30) Ibid., p. 20. 
de responder a esta pregunta, es preciso hacer un recuento del desarrollo y expansión de la idea evolutiva, en la historia de la Sociología.

Desde Ccmte, pasando por Spencer y continuando con la Escuela Histórica o Clásica y los adictos al darwinismo social, la teoría de lo evolución dominó los estudios de Sociología hasta muy entrado el presente siglo.

La €volución en el sistema de Comte se encuentra no sólo en el desarrollo de la mente humana, creadora de la ciencia, sino también en el propio conteniclo de su Sociología como recapitulación de tres supuestos períodos sucesivos.

Entiendo por Física social -escribió el sociólogo francés en 1825 , y lo reprodujo en 1854 al editar su "Sistema de Política Positiva" - la ciencia que tiene por objeto propio el estudio de los fenómenos sociales. Estos, en tanto que humanos, dijo entonces, están comprendidos en la fisiología, pero la positiva influencia de las generaciones, unas sobre otras, no pueden ser estudiadas desde el punto de vista meramente fisiológico. (31).

La Física Social de Comte se proponía explicar el fenómeno del desarrollo de la especie humana, considerando en todas sus partes esenciales; es decir, decubrir mediante que encadenamiento necesano de transformaciones sucesivas el género humano ha sido conducido gradulamente hasta el punto en que hoy se encuentra la Europa civilizada, partiendo de un estado apenas supericr al de las sociedades de los grandes monos. (32) Esta ley de crecimiento consiste, para Comte, en el desarrollo cada vez mayor de nuestra humanidad sobre nuestro animalidad.

Fero Comte trata el mundo histórico social desde un punto de vista muy distinto de los usados por los evolucionistas posteriores. Para él, el desarrollo de la mente humana, el trónsito de la etapa metafísica a la positiva, no significa otra cosa que la comprobación creciente de la necesidad del gobierno de la inteligencia para el bien de la humanidod. La religión positiva, como pináculo de la evolución humana, ha. bría de desterrar para siempre los gobiemos locales y eminentemente políticos, para reemplazarlos por un gobierno de la humanidad y para la humanidod, en el cual los hombres de ciencia serían los dirigentes y realizadores de los ideales del positivismo.

La sociedad fue, para la filosofía positiva, un punto de partida y el único propósito fundamentaal de todo su sistema.

(31) Comte, Primeros ensayos, etc., p. 201.

(32) Ibid., p. 201. 
Por esto su Sociología se convirtió en una historia interpretativa, puesto que, habiendo surgido de las ciencias preliminares por un proceso regular y siendo el fin último del espíritu positivo en sí, tenía que orientarse hacia un sistema probatorio de los beneficios de la inteligencia, logrados para la humanidad por su evolución cada vez más creciente y firme. En este sentido, el evolucionismo de Comte tuvo un objeto prefijado y las tres etapas del desarrollo : teológico, metafísico y positivo, no fueron otra cosa que el examen del desenvolvimiento de la inteligencia y de su consecuente concepción del mundo. La historia, por esto, tenía que estar íntimamente ligada a la mentalidad humana, puesto que era solo realización del intelecto.

En 1857 la teor:a de la evolución adquirió forma y doctrina definidas con la incursión de Herbert Spencer en los campos de la Sociología.

La obra de Spencer, a este respecto, es monumental y su influencia se ha ejercitado poderosa en multitud de investigadores de la sociedad, entre los que merecen citarse Novicow, Lillienfeld, Schäeffle, Worms, Durkheim, Hobhouse, Small, Summer, Giddigns, Ward y otros más. Su abundante producción bibliográfica ha circulado por todo el mundo, en numerosas reediciones y traducciones.

La pujanza de los razonamientos de Spencer, sobre la base de su conocimiento científico natural, evitó, en la segunda mitad del siglo XIX, mayores oposiciones a sus interesantes teorías sobre el desarrollo y evolución de la vida $\varnothing$ de la sociedad. La recepción de su pensamiento se produjo con excepcional rapidez por los pensadores no ingleses, difundiéndose en esta forma la teoría de la evolución a gran parte de las investigaciones sociológicas de entonces.

La resistencia de los ingleses a estudiar la obra de Spencer, se debió no a un repudio de sus ideas metafísicas sino, ia su falta de fornación universitaria, aunque dicha actitud fue rectificada en los últimos años de la vida del filósofo.

En "El Progreso; su ley y su causa", aparecido en 1857, se definió por primera vez como partidario de la teoría evolutiva que a la fecha había dominado las investigaciones biológicas en Alemania, sobre todo con la obra de Baër, de quien asimiló su célebre principio de la heterogeneidad de los procesos.

Las investigaciones de Wolf, Goethe y von Baër, afirma, han comprobado el hecho que los cambios operados en la transformación de la semilla en árbol y del óvulo en animal, estriban en el tránsito de la estructura homogénea a la estructura heterogénea. Pues bien, esta ley del proceso orgánico es la ley de todo progreso. Sea el des- 
arrollo de la Tierra, la vida, la sociedad, del gobierno, la industria, el comercio, el lenguaje, la literatura, la ciencia o del arte. la misma evolución de lo simple a lo complejo subsiste íntegramente a través de diferenciaciones sucesivas. Desde los primitivos cambios cósmicos que se tiene noticia, hasta los más recientes resultados de la civilización, encontramos que todo el progreso consiste, esencialmente, en la transformación de lo homogéneo a lo heerogéneo. (33).

En 1862, con la aparición de "Los primeros principios", añadió Spencer nuevos fundamentos a su teoría. Su ley básica se funda en la persistencia de la energía, de la cual se derivarían la indestructibilidad de la materia y continuidad del movimento. La persistencia de las relaciones entre las fuerzas, la transformación y equivalencia de las mismas, la dirección del movimiento según la línea de menor resistencia o de mayor atracción y la ley del ritmo del movimiento, contribuyen también a configurar la ley de evolución. Mientras todas estas fuerzas no esten en $\in$ quilibrio, tiene que producirse en el universo incesantes redistribuciones de materia y movimiento. La evolucón, pues, es una'integración de materia y una disipación concomitante de movimiento, durante los cuales la materia pasa de una homogeneidada indefinida e incoherente a una heterogeneidad definida y coherente, y el movimiento retenido experimenta una transformación paralela. (34).

El límite de toda evolución es el equilibrio último, y el reverso de ella la "disolución" producida por la pérdida de materia y de energía y la absorción de movimientot ( 35$)$.

(33) Spencer, Progress: Its law and cause, etc., Essays, vol. I, p. 10.

(34) Spencer, Primeros Principios, etc., p. 349.

(35) En el prólogo al resumen de la filosofía sintética, efectuado por F. Howard Collins, el propio Spencer adicionó, en 16 proposiciones, una síntesis de su teoría de la evolución, a saber:

1.-En todo el Universo, en general y en detalle, existe una redistribución incesante de materia y movimiento.

2.-Esta redistribución constituye evolución ahí donde predomina una integración de la materia y una disipación de movimiento, y constituye disolución ahí donde predomina una absorción de movimiento y una desintegración de la materia.

3.- La evolución es simple cuando el proceso de integración, o la formación de un agregado coherente, se verifica sin complicación con otros procesos.

4.- La evolución es compuesta cuando simultáneamente con este cambio primario de un estado incoherente a un estado coherente, se producen cambios secundarios, debidos a diferencias en las circunstancias de las diversas partes del agregado. 
El tránsito de la homogeneidad a la heterogeneidad en la sociedad se evidencia, para Spencer, en multitud de ejemplos entre los cuales el más elocuente es el producido por el aprovechamiento del vapor en la locomotora. Esta, afirma, como causa inmediata de nuestro sistema de caminos de hierro, ha transformado el aspecto del país, la marcha del comercio y los hábitos de todos. La construcción de un camino de hierro significa preparativos, reuniones públicas, el estudio de las sec-

5.-Estos cambios secundarios constituyen una transformación de lo homogéneo a lo heterogéneo, transformación que, como la primera, se muestra en el universo, como un todo, y en todos (o en casi todos) sus detalles: en los agregados de estrellas y nebulosas; en el sistema planetario; en la tierra como masa orgánica, en cada organismo vegetal o animal (ley de von Baër); en el agregado de organismos a través de las edades geológicas; en el cerebro; en la sociedad; en todos los productos de la actividad social.

6.-El proceso de integración, operando tanto local como generalmente, se combina con el proceso de diferenciación para hacer que este cambio sea, no simplemente de la homogeneidad a la heterogeneidad, sino de la homogeneidad indefinida a la heterogeneidad definida; y este rasgo de creciente determinación que acompaña a la característica de creciente heterogenidad, se muestra, como en ella, en la totalidad de las cosas, y en todas sus divisiones y subdivisiones hasta lo más íntimo.

7.-Simultaneamente con esta redistribución de la materia que compone todo agregado que se desarrolla, se produce una redistribución del movimiento retenido por sus compuestosen sus mutuas relaciones. Esto se hace también, poco a poco, más definidamente heterogéneo.

8.-En ausencia de una homogeneidad que sea infinita y absoluta, esta redistribución, de la cual la evolución es una fase, es inevitable. Las causas que necesita son:

9.-La inestabilidad de lo homogéneo, que es consecuencia de la diferente exposición de las diversas partes de todo agregado limitado a fuerzas incidentes. Las transformaciones que resultan de aquí, se ven complicadas por:

10.-La multiplicación de efectos; toda masa, y parte de una masa sobre la cual recae una fuerza, subdivide y diferencia dicha fuerza, la cual, por consiguiente, procede a operar una diversidad de cambios; y cada uno de éstos engendra, a su vez, cambios que se multiplican de un modo semejante; la multiplicación de éstos se hace mayor a medida que el agregado se va haciendo más heterogéneo. Y estas dos causas de diferenciación creciente son favorecidas por:

11.-La segregación, que es un proceso que tiende siempre a separar unidades desemejantes y a unir las unidades semejantes, sirviendo así, continuamente, para agudizar o hacer definidas las diferenciaciones que obedecen a otra causa.

12.-El equilibrio es el resultado final de estas transformaciones que experimenta un agregado en curso del desarrollo. Los cambios prosiguen has- 
ciones de trazado, la intervención parlamentaria, los planos litografiados, etc., cosas que determinan multitud de transaciones, trabajos de campo, fabricación de máquinas, ténders, coches, y vagones, todo lo cual influeye en numerosos ramos del comercio, en el aumento de la importación de la madera, en el trabajo de la piedra, en la fabricación del hierro, en la extracción del carbón, en los hornos de ladrillos, etc., y muchas nuevas ocupaciones como son las de los maquinistas, fogoneros, encargados de la limpieza, guarda agujas, etc., camino de hierro que por su influencia modifica más o menos la organización de todos los negocios. (36).

ta que se logre un equilibrio entre las fuerzas a que están expuestas todas las partes del agregado, y las fuerzas que dichas partes oponen a ellas. El equilibrio puede pasar por un momento de transición, de movimientos que se compensan (como en un sistema planetario) o de funciones que se compensan (como en un cuerpo vivo) en su curso hacia un equilibrio definitivo; por el estado de reposo en los cuerpos inorgánicos o la muerte en los orgánicos, es el límite necesario de los cambios que constituyen la evolución.

13.-La disolución es la contrapartida que más tarde o más temprano experimenta todo el agregado que se desarrolla. Permaneciendo expuesto a las fuerzas que lo rodean, que no están equilibradas, cada agregado corre el peligro de ser disuelto por el incremento, gradual o súbito, del movimiento que contiene; y esa disolución que experimenta rápidamente los cuerpos hasta entonces animados, y lentamente las masas inanimadas, será sufrida en un periodo indefinidamente remoto, quedando completo así el ciclo de sus transformaciones.

14.-Este ritmo de evolución y disolución que se realiza durante cortos períodos en los pequeños agregados, y en los inmensos" agregados diseminados por el espacio en períodos que son inmensurables para el pensamiento humano, es, hasta donde podemos ver, universal y eterno; cada frase alterante de este proceso predomina - ya en esta región del espacio, ya en aquellasegún lo determinen las condiciones locales.

15.-Todos estos fenómenos, desde sus grandes rasgos a sus más diminutos detalles, son los resultados necesarios de la persistencia de la fuerza bajo sus formas de materia y movimiento. Dadas éstas en su conocida distribución a través del espacio y siendo inmutables sus cantidades, tanto por incremento como por disminución, resultan inevitablemente estas continuas redistribuciones, que distinguimos como evolución y disolución, así como aquellos rasgos especiales ya enumerados.

16.-Aquello que persiste, inmutable en cantidad, pero en continuo cambio de forma, bajo las apariencias sensibles que el universo nos ofrece, trasciende del conocimiento y de la comprensión humanos; es un poder desconocido e incognoscible, que estamos obligados a aceptar como algo sin límite en el espacio y sin comienzo en el tiempo.

(36) Spencer, Progress, etc., p. 37. 
Un principio que, para Spencer, regula el desarrollo de la homa geneidad a la heterogeneidad es que "toda fuerza activa produce más de un cambio y toda causa produce más de un efecto", a cuyas consecuencias los resultados se multiplican tanto en número como en especie, en la misma proporción que crece la heterogeneidad del área a que una fuerza se aplica. Entre las tribus primitivas que primero conocieron el caucho, tal descubrimiento produjo muy pocos cambios; éstos, por el contrario, han sido tantos entre nosotros que para hacer su historia es necesario un libro especial. (37).

En 1876, en los "Los Principios de Sociología", consideró los cambios sociales, La forma de obrar de un cuerpo inanimado -asegura Spencer- depende a la vez de los factores que lo constituyen y de las energías que actúan sobre él. Lo mismo sucede con las sociedades, puesto que los fenómenos sociales resultan de la acción combinada de "elementos externos" como la temperatura, la constitución geológica, flora, fauna, etc., y de "elementos internos", tales como los caracteres físicos, morales o intelectuales de los individuos.

Además de estos elementos originarios, Spencer considera los secundarios, provenientes de los primarios y que la misma evolución social pone a contribución. Estos serían : las modificaciones progresivas del medio, inorgánico y orgánico, como efecto de las acciones sociales; el aumento de volumen del agregado social, que por lo general va acompañado de un aumento de densidad; la influencia recíproca entre la sociedad y sus unidades, la del todo sobre las partes, y de las partes sobre el todo; la acción y reacción que se entablan entre una sociedad y las socieãades próximas; "y la acumulación de productos superorgánicos co. mo los instrumentos materiales, el lenguaje, la escritura, la imprenta, las ciencias, las costumbres, las ceremonias, y la conducta. (38).

Admitido por Spericer el principio fundamental que los fenómenos sociales dependen en parie de la naturaleza de los individuos y en parto de las fuerzas que obran sobre ellos, asegura que ambos sistemas de faclores se amalgaman progresivamente con otros, conforme aquuellos van en aumento, produciéndose cisí el tránsito de la homogeneidad a la heterogeneidad.

Pero en Spencer está también el germen de la escuela Bio-organicista, que produjo un movimiento independiente $\mathrm{y}$ casi paralelo al de la tearía de la evolución. Y esta inclinación se produjo porque advirtió los inconvenientes de una evolución unilineal, en la sociedad, sin refe-

(37) Ibid.', p. 58.

(38) Spencer, Principios de Sociología, etc., Caps. ii, iii y iv. 
rirla a cierta ordenación preestablecida, como sucede en el desarrollo de los organismos animados de vida. De ahí su afirmación que hay tres clases de evolución : la inorgánica, que comprende la astrogenia y la geogenia; la orgánica que abarca los fenómenos físicos y psíquicos de los agregados vivientes; y la superorgánica, de los agregados sociales. (39).

Resulta entonces que la Sociedad es un organismo en el cual se puede observar, al igual que en los organismos vivios, el crecimiento o aumento de masa, la complicación de la estructura a medida que aumenta el volumen; la diferenciación de funciones a consecuencia de los cambios estructurales; y la alteración del todo por la modificación de las partes. (40). Sólo concede Spencer una diferencia : en el organismo vivo la conciencia se concentra en una pequeña parte del agregado, mientras que en el social todas las unidades poseen conciencia en grados más o menos semejantes. (41).

Las sociedades, como los cuerpos vivos, nacen de gérmenes, esto es, de agregados elementales. Pequeñas hordas errantes dan origen a las grandes sociedades, gracias al principio de la integración de materia. Ahora bien, el crecimiento puede hacerse por la simple muliplicación de unidades, o por la unión de grupos que van a formar agregados cada vez mayores. En este sentido, a medida que una tribu va aumentando el número de miembros, se va extendiendo sobre una superficie cada vez mayor hasta perder cohesión e independizarse en tribus distintas, incluso con lenguas diferentes. COtro modo de crecimiento sociaì son las migraciones.

Al lado de este proceso de integración, las sociedades como los cuerpos vivos, presentan la diferenciación. En el proceso de los pequeños grupos a los grupos mayores, la diferencia de las partes hace que vaya aumentado la heterogeneidad. Por ejemplo, donde las familias viven a iniervaios distantes, la organización social es imposible, pero donde los grupos se integran existe siempre un gobierno, una clase trabajadora distinta de la reguladora, y así sucesivamente hasta establecerse diversos grados de complejidad. (42).

La sociedad como organismo ostenta un aparato productor, representado por las diversas industrias; un aparato distribuidor, tales como las vías de comunicación, la circulación de mercaderías, las ferias y

(39) Ibid., Caps. I, p. 2 y sgs.

(40) Ibid., II parte, Cap. I.

(41) Ibid., II parte, Cap. II.

(42) Ibid., II parte, Caps. III y IV. 
los mercados, etc.; y un aparało regulador, formado por un centro coordinador superior que ejerce una acción directriz sobre los centros inferiores. (43).

Los organismos sociales se agrupan, según la clasificación de Spencer, en sociedades simples, consideradas como tales las que forman un todo no sujeto a otro y cuyas partes cooperan, con o sin un centro regulador, a determinados fines de interés público; sociedades compuestas, o sea aquellas que en algún grado los jefes de los grupos simples se encuentran subordinados; sociedades doblemente compuestas, que abarcan aquellas sometidas a un gobierno más elevado o las formadas por la combinación de los grupos compuestos; y las triplemente compuestas, representadas por las naciones civilizadas. Estos tipos de sociedades son grados que toda agrupación debe atravesar sucesivamente. (44).

Por otra parte, según el género de actividad social predominante, considera Spencer otros dos tipos de sociedades; el militar y el industrial.

El primero, es aquel en que el ejército es la nación movilizada, convirtiéndose el jefe militar en jefe político, autoridad que se vuelve permanente dentro de una raza conquistadora. Tal estructura se reproduciría en todos los demás aspectos sociales, apareciendo clases, e incluso castas, subordinadas unas a otras. La religión, en estas sociedades, tendría también caracter guerrero, conformando un gobierno sobrenatural.

El segundo, presenta una forman de gobierno menos coercitiva $y$ facilita el desarrollo de la libertad política. En los países industriales la religión va perdiendo pcco a poco su fuerza y jerarquía rígida, y se produce una evolución desde la esclavitud hasta la libertad de asociación y trabajo. En lugar de la obediencia ciega al gobernante reina la doctrina de la soberanía de la voluntad del ciudadano, de la cućl ei gobernante no es sino un mandatario.

La escuela biológica alemana, propuso una diferenciación de la homogeneidad a la heterogeneidad, pero a base de organismos, de estructuras vivas que debían seguir una regla de conformación en su ulterior desarrollo, proceso en el cual siempre hay un principio generador, un arquetipo proporcionado por la especie, una necesidad dentro de la evolución, pues nunca se dará el caso que de una semilla de tri-

(43) Ibid., II parte, Cap. VI á IX.

(44) Ibid., LL parte, Cap. X. 
go se desarrolle un árbol de manzano. Esta canalización del proceso biológico le dio a la teoría de la evolución orgánica una limitación que hacía posible la explicación científica del clesarrollo de las estructuras vivas. Pero on Spencer este límite desaparece a fin de hacer posible la aplicación del principio a todo desenvolvimiento universal.

El gran defecto de su teoría, aplicada a la sociedad, estriba en el falso plantamiento de ésta como organismo, al igual que los estudiados por las ciencias de la vida. No entraré en mavores discriminaciones sobre este punto toda vez que serú objeto de un capítulo especial más aielante, al cual me remito desde ahora. Fero desaparecido $\equiv l$ concepto organicista, las teorías de Baër resultan inaplicables a la sociedad, puesto que ya no cuentan con su principal sustento, cual era el desarrollo superorgánico.

Y sobre torjo, ¿en qué consiste la homogeneidad y la heterogeneidad sociciles? No hay un criterio establecido para calificar determinadas instituciones o prácticas desde esos puntos de vista, y mal podemos afirmur que el sistema de parentesco totémico, con sus múltiples combinaciones y reglas, sea más homogéneo que el sistema latino contem. poráneo. Si deseáramos encontrar homogenidad en el primero sería tan sencillo como encontrala en el segundo, e, igualmente, si se observa el desarrollo del derecho en las diversas sociedades del mundo, pcdemos afirmar que la desaparición de su formalismo lo hace hoy día mucho más nomogéneo que antaño. Esto demuestra que los conceptos de homogeneidad y heierogeneidad no pueden ser aplicados, válidcmente, a las instituciones y acciones sociales doda vez que es inadmi. sible tratar a los hechos de los hombres al igual que los hechos de lo naturaleza.

Hay en el mundo histórico social una serie de actividades permanentes, de prácticas sociales eternas, cuya casuística varía de época a época y de circunstancia a circunstancia, pero tales variaciones sı constituyen, ciertamente, el sentido de sus realizaciones.

Averiguar la significación de una institución y su finalidad última es, esencialmente, la tarea de la Sociología. Lo demás queda para una historia de las costumbres o una exposición ordenada de la cultura.

Por otra parte, Spencer equivocó el concepto que lo anterior en el tiempo debía ser más sencillo en estructura. El protoplasma es mucho más complejo de lo que aparece a primera vista, y la vida primitiva ofrece mayores complicaciones que la vida social moderna. Los ritos mágicos, el formalismo de los actos humanos, la organización social y el sistema totémico, etc., nos ofrecen una heterogeneidad que Spencer se esforzó en disimular. 
Pero la teoría de la evolución no sólo recibió el aporte de Spencar. En 1859, tres años antes de la aparición de "Los Primeros Principios". Carlos Darwin publicó su obra "El origen de las Especies", que sirvie. ra de antecende a su segundo libro "La ascendencia del hombre y la selección sexual", sacado a luz en 1871.

La obra de Darwin contribuyó a afianzar, desde otro punto de vista, al evolucionismo en la sociología. En efecto, para el biolćgo inglés, nada en el hombre es innato, pues tanto su cuerpo como sus facultades mentales presentan serios síntomas de haberse derivado de especies infericres. Las mismas faculiades mentales ya existían, mucho anies de que el hombre apareciera como especie, en todos los animales inferiores. Tampoco, manifiesta Darwin, es nada nuevo para el hombre la sociabilidad, pues también es común a algunas especies de animales inferiores, especialmente los cuccirumanos.

Ia especie humana, pues, llevaría en su naturaleza todas las conquistas de sus antecesores, algunas más desarrolladas que otras, medionte las cuales y siguíendo un proceso de desenvolvimiento, se ha colocado en un plano muy superior a las demás, lo que significa: para el naturclista, la existencia cle la ley de la evolución ya anunciada en su libro "El origen de las Especies".

Pero, ¿cuál es el fundamento de esta ley evolutiva? Darwin lo explica apelando a la acción de lás funciones seguido, en sus órganos respectivos, de cambios de estructuras que permiten realizar mejor la función suplementaria y, por consiguiente, cuando un individuo se halla en actitud, por cierta particularidad de su estructura, de realizar mejor que otros alguna ccción ventajosa, trasmite a sus descendientes un número mayor o menor de las particularidades de la estructura que posee; y entre estos descendientes, los que se encuentran mejor dotados tienen mayor probabilidad de prosperar y propagarse, produciéndose $\alpha$ sí, merced a la acción contínua de las estructuras sobre la función, un tipo de estructura visiblemente modificado, que posee una función más o menos distinta.

De idéntica manera trabaja la selección natural. Los antiguos antecesores del hombre, expresa, se habían inclinado a multiplicarse mucho más de lo que les permitían sus medios de subsistencia, librando una contínua lucha por existir; y esta selección natural, modificando las condiciones biológicas del hombre. se ayudó, además, con la transmisión hereditaria de los órganos desarrollados por el aumento de uso. (45).

(45) Darwin, El origen del hombre, etc., Cap. II, p. 28. 
La supremacía y supervivencia del hombre en un medio tan hostil se ha debido, según el naturalista, a tres cualidades adquiridas y desarrollados por selección naiural : intelecto, conformación corporal y hábitos sociales.

Las cualidades intelectuales de la especie humana permitiercn crear el lenguaje, inventar las armas y descubrir el fuego, productos culturales que afianzaron su predominio en la naturaleza.

La conformación corporal manifestó su influencia en la colocación de los músculos de la espalda y brazos que facilitaron, al antecesor del hombre, arrojar piedras con perfección; en la forma de la mano que lo llevó al tallado del pedernal o la fabricación de anzuelos de huesos; en el hecho de ser bípedo gracias a que adquirió la costumbre de vivir menos en los árboles y más en el suelo, lo que le proporcionó libertad en los brazos y parte superior del cuerpo; y en los pies planos que le permitieron reposar el cuerpo sobre ellos y servirse mejor de sus extremidades superiores.

Por último, los hábitos sociales han permitido al hombre desarrollar la superioridad de su especie. En los animales rigurosamente sociales, la selección natural obra algunas veces indirectamente sobre el indivialuo, conservando sólo las variaciones que son útiles a la comunidad. La inquietud de ser separados de sus compañeros, la advertencia mutua del peligro y la ayuda en la defensa, han sido adquiridos por los antecesores del hombre, según el naturalista, por selección natural. Mejorando el raciocinio y la previsión, cada cuál aprende pronto que si ayuda o sus semejanteséstos de ayudarán a su vez, y así los hábitos seguidos durante muchas generaciones se trasmiten a los descendientes por herencia, adviniendo en facultades institivas. La sociabilidad se transforma en instinto, que ocasiona placer cuando se reali$z a$, y se constituye por extensión de los afectos de familia, que le sirven de base. (46).

Sin embargo, a pesar de lo expuesto por Darwin, puede afirmarse que en el hombre no es necesario se produzca un proceso de selección natural para convencerlo que solamente con la ayuda de sus semejantes (sociabilidad) puede vencer al medio en que vive. El razonamiento y la selección natural, en el establecimiento de las relaciones de personas, son completamente ajenos, y no pueden ser factores determinantes de dichas vinculaciones, las mismas que presentan una fenomenología especial, diferente de todo raciocinio. Hay que tener en cuenta que Dar-

(46) Ibid., Cap. V, p. 171 y sgs. 
win pone las facultades intelectuales, el reconocimiento de las conveniencias de la asociación, como fundamento de la sociabilidad que posteriormente se iría a convertir en instinto y por lo tanto trasmitirse por la herencia, sin darse cuenta que con esto convertía al hombre primitivo, o a su antecesor, en un ser eminentemente racional, capaz de discriminar entre los instintos individuales y sociales y comprender que la vida en sociedad proporciona la felicidad de todo el conjunto, conceptos estos que a la fecha se encuentran completamente superados.

No obstante, la obra de Darwin, unida a la de Spencer, abrieron una nueva época en las investigaciones histórico sociales. A partir de entonces la teoría de la evolución se convirtió en la clave universal para la explicación de cuantos fenómenos se presentaren a la problemática de las ciencias, material o espiritual. $Y$ es que su planteamiento naturalístico ofrecía todas las ventajas que la tradición positiva de entonces exigía.

Después de Darwin y Spencer, la teoría de la evolución tomó dos direcciones opuestas : la seguida por el darwinismo social y la adoptada por la escuela clásico o histórica.

Los teóricos del darwinismo social se impresionaron con las ideas de la lucha por la existencia y selección natural, para la explicación de los procesos sociales.

Los mejores representantes de esta escuelo son : Gumplowiez, Ratzenhofer, Novicow, Vaccaro y Lester Ward, aparte de otros muy numerosos sociológos que hacen de la guerra y la selección la clave para la comprensión de la evolución.

Gumplowicz no omitio razones para enunciar Sleyes universales aplicables al desarrollo y evolución de la sociedad, que se fundaran en el principio cardinal de su sistema; la lucha por la existencia.

Hay siempre un proceso social - manifiesta- cuando dos o varios grupos sociales heterogéneos se ponen en contacto y se penetran recíprocamente en sus esferas de acción. El juego de las fuerzas naturales que, constituye el proceso social, comienza desde el momento en que un grupo está sometido a la acción de otro, cuyo primer impulso es siempre la tendencia natural de cada uno de ellos a explotar al contrario. Este proceso, en virtud de la infinita diversidad de especies de las hordas y tribus, y luego a causa de las diferencias entre las formas y comunidades sociales que entran a la vez en contacto, presenta una gran variedad de desenvolvimientos individuales, y buscar y encontrar todos estos diferentes desarrollos, las leyes que obran en ellos y los rigen, explicar dichas variedades con ayuda de las fuerzas activas más simples, reunir las innumerables formas del desarrollo social bajo los 
nombres comunes más sencillos, tal sería la grande y difícil tarea de la Sociolcgía.

Gumplowicz (47) asegura que en todo proceso natural se puede observar dos faciores esenciales; de una parte los elementos heterogéneos y de otra la acción recíproca de dichos elementos, unos sobre otros. De igual manera, el proceso sociológico es también, para el autor austriaco, un proceso natural, toda vez que se puede encontrar en su constitución los dichos elementos. Los heterogéneos son aquí los grupos étnicos, las inumerables bandas humanas que se nos han revelado como el rnás lejano comienzo de la existencia de la humanidad; y las acciones determinantes que esos elementos ejercen unos sobre otros se encuentra en que todo elemento étnico busca, para servir a sus fines, al más débil que se encuentre en su radio de potencia o que penetre en él. Veremos siempre -continúa el autor- realizarse esta tésis, en el pasado y ahora, pues no otra cosa es la matanza de los miembros de una tribu extraña por aquella que, no consiguiendo hacer concurrir a sus fines a las otras bandas, lo hace en esta forma, para, posteriormente $y$ en un grado ulterior de desarrollo, reconocer que no se puede utilizar mejor para los propios fines el elemento social extraño que ocupándolo en los servicios más diferentes. Se realiza así un gran progreso, con la esclovitud y las servidumbres, o con las alianzas y las confederaciones. Pero la universalidad de este principio motor de los procesos sociales se encuentra, en el sistema de Gumplowicz, en cque lo que ocurre en pequeña escala entre las tribus primitivas de los pueblos en estado de naturaleza se renueva en un grado superior entre las naciones civilizadas, cuyas guerras son nuevas formas de aquellas expediciones de pillaje.

Novicow, (48) por su parte, afirma que el resultado de la lucha es la eliminación de los menos aptos y la supervivencia de los mejores dotados, o de aquellos que pueden adaptarse a las condiciones exteriores.

La lucha por la existencia había adoptado, a través de su evolución, cuatro formas sucesivas; la fisiológica, la económica, la política y, por último, la intelectual. La primera tuvo como fin principal la obtención de los alimentos, como por ejemplo, el canibalismo. La segunda,

(47) Gumplowicz, Compendio, etc., p. 138 y sgs.; La Lucha de razas, etc., p. 154 y sgs.

(48) Novicow, Las luchas entre las sociedades humanas, etc., ps. 1, 30. 
persigió la adquisición o apropiación de bienes para la acumulación de la riqueza, que dio lugar a las guerras económicas, al pillaje o bandolerismo y a las diversas formas de competencia comercial. La tercera, se dirigió hacia la consecusión de poder o dominio sobre ciertas partes de la sociedad, originando las guerras de expoliación, conquistc, anexión, etc. La cuarta y la última, procura el triunfo de alguna ideología, sec relígiosa, filosófica, etc., Cree Novicow que la lucha no desaparecerá, pero cue irá siendo reemplazada por formas de competencia intelectuod.

En América, el darwinismo social tuvo su mejor representante en Lester F. Ward, quien en sus libros "Dynamic Sociology". New Yark, 1883; The Psychic Factors of Civilizction", Boston 1893. "Outlines of Sociology": Washington, 1897 y "Pure Sociology", 1903, adoptó los principios generales del positivisma, la teoria de la evolución funcada en Spencer, y sobre todo, la idea de la lucha de la escuela darwinista.

Todo el sistema sociclógico de Ward se reduce al estudio de las combinaciones de las distintas fuerzas sociales, bien sea en cantagonismo o en cooperación, para explicar la idea general de la evolución $\alpha$ plicada al mundo hisiórico social. Acusa un afón innecesario de adoptar la terminología de las ciencias físicas y biológicas a los concptos que expone en su Sociología. incurriendo en el defecto general de la época de establecer anclogías entre los grupos humanos $Y$ los crganismos o combinaciones físicas. Era el prurito científico natural que dominaba los tratados de entcnces, en el deseo íntimo do despejar cualquier duda sobre la validez universal de las disciplinas que se ocupaban del hombre y sus produptos. cinelli Converso"

Según Ward, la asociación se produjo muy primitivamerte $Y$ en un estado subhumano por completo, $Y$ constituye el fundamento principalísimo de las instituciones sociales. (49).

La causa del hecho primario cie la asociación la coloca en el apetito o deseo de satisfacción de alguna necesidad, considerando que la forma simple de sentir es agradable o desagradable, placentera o dolorosa. El deseo, como inclinación de evitar el dolor y buscar el placer, es la que constituye, para el sociólogo nortecmericano, la fuerza social.

Todas estas fuerzas, obrando conjuntamente, conforman el proceso genético de la sociedad o génesis social. Tal proceso es la obra ciega e inconsciente de las fuerzas sociales que, trabajando para el perfeccionamiento humano en el estado colectivo, es lo que constituye la evolución social.

(49) Ward, Pure sociology, etc., p. 193. 
Las fuerzas sociales, dentro de un mismo grupo o dentro de grupos diferentes, luchan y chocan unas con otras, se oponen entre sí y tienden constantemente al reposo, o sea que buscan un estado de equilibrio que traiga como resultado general la formación de estructuras e instituciones. Esto es lo que conforma, para Ward, el principio de la synergia social.

Mediante ella se consigue una ccoperación de fuerzas antitéticas por una sucesión de procesos : colisión, lucha, antagonismo, oposición. competencia, interacción, compromiso, colaboración, cooperación y organización. Este camino lo explica claramente cuando se ocupa de la formación del Estado. Considera Ward que el origen de los grupos antagónicos es la reproducción de una sola pareja que, al transcurso de varias generaciones, produjo diversos grupos que olvidaron su origen, se diversificaron por acción del medio en sus características, y se encontraron aislados unos de otros. Es la etapa protosocial. Sin embargo, muy pronto a esta diferenciación sucede una integración social, como resultado de la inter-acción de fuerzas antagónicas, que producen la hostilidad entre los grupos, la guerra y la conquista de los más débiles. Por este medio se unen dos o más hordas simples en un grupo compuesto, principiando la etapa metasocial. El primer resultado de la conquista es el establecimiento de un sistema de castas, la consideración económica del trabajo y la aparición de la propiedad privada de la tierra. Por otra parte, la constante represión a que se encuentra sometida la casta subyugada propicia la formación de reglas generales que acaban por convertirse en leyes que reemplazan los mandos arbitrarios. Todos estos resutados constituyen nada menos que el origen del Estado.

Dosteriormente a la fundación de este instituto, la lucha por la existencia ocasiona la cooperación entre las dos razas opuestas por la conquista, inicióndose la decadencia del antiguo orden y prejuicios, y terminando con la mezcla de los opositores y oponentes. El resultado es la formación de la nación.

El estado de equilibrio de las fuerzas sociales es, para Lester Ward, lo que constituye la Estática Social, que comprende las estructuras, mientras permanezcan siendo las mismas, aún cuando se hayan desenvuelto y multiplicado. Le corresponde el estudio del orden en la sociedad;

Sin embargo, los agentes que producen el origen y el desenvolvimiento de una estructura o institución, continúan actuando en la misma dirección, hacia su modificación y transformación, fenómenos propios de la Dinámica Social. La remoción de obstáculos al deseo es la 
causa íntima de todo progreso, que da por resultado la transformación del medio, la modificación de las estructuras sociales existentes y la producción de otras nuevas.

El sistema sociológico de Lester F. Ward termina con la Télesis social, verdadera utopía que propiciaba el sociológo con un ardor y convicción solamente comparada con la que uso Comte al patrocinar el pontificado de la religión positiva. Cuando la génesis social, dice, adquiere su máximo desarrollo, la sociedad despierta a la conciencia colectiva, iniciándose el período télico del proceso. La transición de una etapa a la otra se debe al desenvolvimiento de la facultad intelectual que, en lo sucesivo, en vez de fuerza, sirve de guía para encontrar pasos alrededor de los obstáculos opuestos al deseo. La Sociología, en este sentido serviría para demostrar, a la inteligencia de los hombres, la forma del mejoramiento social.

La aplicación de la Sociología a la vida práctica y diaria, y sobre todo el establecimiento de las reglas de un progreso continuado, es lo que ha denominado Ward la sociocracia, llamada a reemplazar "la democracia inepta" de sus días..

Todas estas teorías tienen un defecto común: su unilateralidad.

Es evidente que en el curso de la vida existen antagonismos y luchas, pero en cambio no llenan todo el campo de la Historia, ni mucho menos, de la Sociología. La ayuda mutua, la solidaridad, la simpatía, etc., desempeñan un papel importante en la causación social.

Kroptkin ha demostrado la falsedad de concebir los vida social primitiva como una lucha desesperada de uno contra todos. En su interesante libro "El apoyo mutuo como factor de progreso entre los animales y los hombres", hace ver que el hecho de existir fuertes organiza. ciones sobre la base de la familia y matrimonio en las hordas, demuestra hasta donde es falsa la opinión que representa a la humanidad primitiva como una turba desordenada de individuos que obedecen sólo a sus propias pasiones y se sirven de su propia fuerza personal y astucia para imponerse a los otros. El individualismo desenfrenado es manifestación de tiempos mucho más modernos, pero de ninguna manera era propio del hombre primitivo. (50).

Durante los siglos de migraciones de pueblos asiáticos hacia Europa, a causa de las sequías en sus regiones de procedencia, a pesar de las grandes conmociones sociales que produjeron, sus uniones basadas en la comunidad de origen, real o supuesta, sirvieron para unirlos du-

(50) Kropotkin, Ayuda mutua, etc., p. 119. 
rante muchos milenios. (51). Más tarde, cuando destruída, interiormente por la familia separada, y exteriormente por el desmembramiento de los clanes debido a la emigración y por la necesidad de aceptar en su medio a los extranjeros, la organización tribal comenzó a descomponerse. En su reemplazo apareció la comuna aldena, basada sobre la concepción de un territorio común, institución que permitió a los bárkaros pasar el período más turbio de su historia sin desintegrarse. Tal fue la nueva forma en que se encausó la tendencia de las masas al apoyo mutuo. (52).

Este apoyo también lo pone de manifiesto Kropotkin en las ciudades medioeval y moderna, con abundante documentación. La tesis de la lucha contínua, como causa de los cambios sociales es, ahora, inaceptable.

La escuela histórica, por su parte, agrupó a cierto número de investigadores de la cultura, que tenían de común no sólo la tradición evolutiva sino, sobre todo, el método comparado, consistente en clasificar lcs datos propcrcionados por las diversas fuentes de información, teniendo en cuenta las instituciones a que pertenecían, sin prestar mucha atención al mayor o menor grado cultural de cada una. Dentro de esta escuela debe mencionarse como sus mejores representantes a Johan Jacob Bachofen, cuya obra "Das Mutterrech", Stuttgart 1861, impulsó considerablemente las investigaciones etnológicas sobre las organizaciones familiares. De igual manera son importantes John Lubbock, "The origen of Civilization". London, 1870; Edward B. Taylor, "Primitive Culiure", London, 1871; Lewis H. Morgan, "Ancient Society", London y New York, 1871 Y Edward Westermarak, "The history of human marriage", London 1891.

Dentro de la escuela, quien adquirió mayor renombre por sus sencillos cuadros evolutivos fue, sin duda alguna, Lewis H. Morgan. Se puede comprender la evolución, afirma en su obra fundamental "La Sociedad Primitiva" publicada en 1877, siguiendo los grandes derroieros que nos dejan los hechos de subsistencia, leguaje, gobierno, familia, religión, vida de hogar, arquitectura y propiedad, es decir a través de dos líneas independientes : los inventos y descubrimientos y las instituciones primitivas. En ambas, la marcha progresiva se mantiene constante desde las formas rudimentarias hasta las complejas contemporáneas; se cbserva que la experiencia del género humano ha corrido por causes casi uniformes; que las necesidades humanadas bajo condicio-

(51) Ibid., p. 151.

(52) Ibid., p. 182. 
nes similares han sido sustancialmente las mismas y que la evolución mental ha sido pareja en virtud de la identidad específica del cerebro en todas las razas humanas. La evolución, para Morgan, se marca en tres grandes épocas sucesivas de la humanidad; Salvajismo Barbarie y Civilización.

Producido el primer empuje evolutivo, cuya iniciación la coloca Morgan en la potencia cerebral del hombre y en su poder inventivo. basta que se produzca posteriormente algún nuevo invento o descubrimiento para que las instituciones sociales alcancen nuevas y variadas formas.

¿Cuál es la razón del progreso humano, según Morgan? Si descendemos a través de las líneas del progreso, afirma, hacia las edades primitivas de la existencia del hombre y descartames uno por uno sus descubrimientos e invenciones principales, en el orden que han hecho su aparición, se puede apreciar el adelanto realizado en cada período.

A medida que ascendemos en el orclen del tiempo y la evolución y descendemos en la escala de los adelantos humanos, las invenciones se tornan más sencillas y más directas en su realización con necesidades primarias; y las instituciones se aproximan más y más a la forma elemental de una gens compuesta de consanguíneos, bajo un jefe de su propia elección, o a la organización de la tribu compuesta de gentes á́ines, bajo el gobierno de un consejo de jefes. (53).

Cuando este trabajo de eliminación haya sido realizado en el orden en que las diversas adquisiciones fueron logradas, nos habremos aproximado muy cerca del período de la infancia de la existencia del hombre, a la época en quéla humanidad ibanaprendiendo el uso del fuego que haría posible una subsistencia a base de pescado, y se ensayaba en la construcción de un lenguaje articulado. En una condición tan absolutamente primigenia, el hombre aparece no sólo como un niño en la escala de la humanidad, sino también poseedor de un cerebro en el que ni un sólo destello o concepto traducido por estas instituciones, invenciones y descubrimientos, ha penetrado; en una palabra, se halla al pie de la escala.

Fuera de duda, las primeras invenciones y organizaciones sociales fueron más difíciles de adquirir, y por lo tanto, los más largos intervalos de tiempo las separan entre sí. La razón del progreso, según Morgan, se encuentra en esta potencialidad de razonar, en la experiencia creadora, que ha conducido al hombre desde el pie de la escala hasta la civilización.

(53) Morgan, La sociedad primitiva, etc., p. 49. 
El desarrollo evolutivo no sólo se presenta en las tres épocaz de progreso sucesivo : salvajismo, barbarie y civilización, sino también se percibe en la línea de las instituciones, como por ejemplo en la familia, gérmen de todo desenvolvimiento social posterior. En efecto, Morgan parte de la horda primitiva con trato sexual promíscuo, para pasar luego al matrimonio y familia consanguíneos; seguir con el matrimonio y familia punulúa; el matrimonio y familia sindiásmico; la familia patriarcal; y, por último, la monogamia. Esta cadena de formas institucionales derivaríase, de eslabón en eslabón, de la primitiva horda o bandas de personas de ambos sexos.

Las dos ramas de la teoría de la evolución : la escuela histórica y el darwinismo social, fueron el fundamento teórico de toda Sociología fundada en dicha doctrina. Pero, a principios de este siglo, nuevos métodos de investigación y nuevas generaciones de etnólogos han desacreditado por completo a la escuela histórica o clásica, principal sustento de la teoría, y con ella a la evolución misma. En 1911, Franz Boas publicó en New York su obra "The Mind of Primitive Man". enunciands. una nueva forma de tratar los fenómenos de la cultura y revolucionando la teorética que hasta entonces se había empleado en las investigaciones biblicgráficas y empíricas. Los trabajos de campo, la formación de investigadores y la elaboración de monografías, fueron la constante preocupación de Boas, obras que, indudablemente, le han colocado en el más alto sitial, dentro de la etnología contemporónea.

Este notable etnológo ataca duramente la teoría de la evolución unilineal, tal como habia sido concebidachasta entonces por los investiqadores de la cultura, y estima que si bien es cierto puede descubrirse semejanzas entre los tipos de cultura representados por pueblos primitivos y las condiciones reinantes entre los antepasados de los pueblos actualmente civilizados en los comienzos de la historia, en cambio aquello no justifica la completa generalización, y para que la teoría del desarrollo paralelo tuviera alguna importancia, sería preciso que en todas las ramas de la humanidad, los pasos de la invención hubieran seguido, al menos aproximadamente, el mismo orden sin dejar brechas considerables. (54).

Para sostener esta afirmación, Boas acude al examen de las actividades agrícolas y ganaderas : las ocupaciones conducentes a la domesticación de animales no tienen nada de común con las que conducen al cultivo de las plantas, no hay lazo que haga admisible una co-

(54) Boas, Cuestiones fundamentales, etc., p. 175. 
nexión entre el desarrollo cronológico de estas dos formas de trabajo. y falta este vínculo porque las personas implicadas no son las mismas y porque las ocupaciones son completamente distintas.

Con este criterio, la teoría de la evolución unilineal, y sobre todo la forma como era concebida y sus métodos, ha quedado de lado por completo, puesto que no es suficiente hacer una recopilación de costumbres $\circ$ de instituciones sin tener en cuenta el complejo a que cada una de ellas pertenece. Si, por el contrario, se investiga una cultura determinada en todos y cada uno de sus aspectos, sin entrar en comparaciones que sólo tengan como base la simple analogía, entonces se llega al convencimiento que las costumbres no se desarrollan necesariamente de la misma manera; y que siendo posible que de una fuenta única se desprendan costumbres diferentes, no hay derecho a suponer que todo pueblo que ha alcanzado un alto grado de desarrollo cultural tenga que haber pasado por las etapas que se encuentran en tribus de cultura primitiva. (55).

Lo fundamental en el estudio de la cultura no es el establecimiento de líneas de desenvolvimiento o evolución, sino la comprensión de la totalidad del complejo cultural, la averiguación de la forma de influencia del sistema económico imperante sobre las costumbres y creencias, así como de éstas sobre aquel y sobre cuaquier otro aspecto de la cultura misma. La comprensión de su sentido es el único camino que nos llevará al conocimiento de cada cultura.

Las nociones fundamentales desarrolladas por Franz Boas, hain sido seguidas de otrás direcciones más o menos similares, que tienen como fin $\mathrm{y}$ de común entre ellas la lucha contra los prejuicios evolutivos. Como representantes de tales tendencias debe citarse a Fritz Graebner, "Etnología", Leipsig, 1923; Wilhelm Schimdt y Wilhelm Koppers cutores de "Volker und Kulturen", Regensburg, 1924, y G. Elliot Smith, "In The Beginning; the Origine of Civilization". New York, 1928.

En la época contemporánea a Cornejo, pues, la teoría de la evolución había sido completcmente destruída, pero, sin embargo, toda su obra está ordenada dentro de los cónones clásicos del evolucionismo, ein sujs dos formas, hábilmente combinadas : el darwiniso social y la escuela histórica.

En resumen, Cornejo afirma lo siguiente : (56).

(55) Ibid., p. 183.

(56) Cornejo, Sociología, etc., Cap. III, p. 161 y sgs. 
1.- Las organizaciones sociales pueden dividirse en dos grandes grupos : domésticas y políticas.

2.- Las organizaciones domésticas son el resultado de un proceso biológico, y pertenecen todas al grupo sociológico de la familia. Por familia entiende toda agrupación simple creada por la generación. Sus sucesivas formas son la horda, el clan, la fratria y la tribu.

3.- Las organizaciones políticas son el resultado de un proceso social, y se forman por la reunión de diversas sociedades domésticas, mediante un proceso de agregación.

4.- En las sociedades domésticas se encuentra el gérmen de toda la evolución posterior de la sociedad. Los primeros sentimientos colectivos se derivan del aspecto, orgánico de los sexos, de la maternidad y del placer físico y moral que dá el hábito de la convivencia

5.- Tres grandes necesidades dominan el grupo : alimentarse, reproducirse y defenderse, las mismas que constituyen fuerzas de cuya organización aparece el proceso social.

6.- A la resistencia que hallan las necesidades nutritivas corresponde la organización económica; a las que encuentra las de seguridad pertenece la organización política; y de los obstáculos opuestos al instinto genésico se deriva la organización de las relaciones de los sexos en el matrimonio.

7.- La necesidadr de conservar lel alimentosindispensable para la vida produce el sentimiento colectivo de la propiedad, y el hecho de $\alpha$ segurar la propiedad y la vida se refleja en la voluntad colectiva de defensa o agresión.

8.- Cuando el ejercicio de esa voluntad difusa se concentra en un órgano, nace la autoridad, la misma que, una vez organizada, otorga la garantía de la fuerza colectiva a los instintos de conservación y reproducción. Esa garantía constituye el derecho.

9.- La autoridad en su forma de derecho, origina el Estado.

10. - El correlato psíquico de estos procesos objetivos que organizan el grupo, son el sentimiento de la conveniencia o incoveniencia de ciertos actos, destinados a convertirse en la moralidad.

11.- Como en el grupo el desarrollo de la vida afectiva y social está acompañado de una evolución paralela del pensamiento colectivo, nacen las creencias y símbolos que forman la religión. 
12.- La especulación crea la ciencia, y cuando la vida psíquica se traduce en formas simplemente representativas, nace el arte.

13.- Toda estructura, y por consiguiente la estructura social, es el resultado de la actuación combinada de mucha fuerzas, que tienden a predominar sobre las otras, hasta conseguir el equilibrio.

14.- El equilibrio que presenta una sociedad supone el conf́licto previo de las unidades, es decir, de los grupos que la componen.

15.- Los grupos étnicos, pues, se organizan socialmente cuando comienzan las resistencias sociales.

16.- Estas resistencias pueden producirse, bien entre las partes de una misma sociedad, o bien entre dos o más grupos entre sí. Cuando son las partes las que se oponen, resulta la diferenciación económica y la división del trabajo; y cuando son los grupos, aparecen la diferenciación política, o sea la organización del grupo como unidad.

17.- Los conflictos sociales pueden ser violentos o pacíficos. Los grupos primitivos tienden a destruírse, pero en una etapa posterior de evolución aprovechan los elementos que no pueden ofrecer resistencia, como las mujeres y los niños, y sólo más tarde, cuando se sienten fuertes, asimilan al grupo vencido en forma de esclavitud.

18.- Estas integraciones provocan conflictos internos que crean la organización de los gupos compuestos.

19.- Las fases del proceso de agregación quer crea los grupos compuestos, es la siguiente : a) sometimiento de una, raza a otra o esclavitud; b) período de casta; c) mitigación de las condiciones anteriores, produciendo un gran estado de desigualdad social y política; d) sustitución de la dominación puramente militar por una forma de ley, origen ael derecho legal; e) creación del Estado en que todas las clases tienen derechos y deberes; f) reunión de la masa de elementos heterogéneos en un pueblo más o menos homogéneo; y g) nacimiento del sentimiento patrio y formación de la nación.

Hasta aquí Cornejo no ha hecho sino asimilar las ideas generales del darwinismo social, tomadas en gran parte de las obras de Lester F. Wara', Gumplowicz y Ratzenhofer, y aquí también, encontramos nuevamente su tendencia sincretista. El conflicto de los grupos no sólo originaría la organización de la sociedad, sino daría lugar, además, a efectos secundarios. El primer efecto de esa lucha de los grupos es el desarrollo de la solidaridad (Durkheim) y la afirmación de la conciencia 
de la especie (Giddings). Ambos factores, auxilióndose mutuamente, crean la cooperación social, que no existió durante el período en que las hordas se dedicaron a la caza exclusivamente, pues sería esta una simple operación individual, mientras que la guerra exige siempre cooperación.

La recepción de los principios de la escuela histórica se encuentran en el segundo tomo de la obra de Cornejo. Cuando trata del desarrollo del lenguaje, mito, religión, arte, costumbre, derecho, moral, matrimonio, familia, Estado y ciencia, con excepcional talento amalgama las ideas de Wundt respecto al alma colectiva, con las investigaciones de la escuela clásica. Morgan, Mac Lenan, Westermark, Frazer etc., se repiten continuamente.

El problema que nos plantea la teoría de la evolución, debe expresarse así : ¿existen cambios en la sociedad y su cultura?

Es evidente que sí existe tales cambios. La economía contemporánea, por ejemplo, no tiene la misma estructura que la economía de la época romana, pues basta citar al asalariado y al esclavo para establecer la diferencia. La moda es otro ejemplo de los cambios sociales.

Ahora bien : ¿cuáles son las causas de estos cambios sociales? ¿La evolución natural?, vale decir ¿la transformación de las formas culturales se lleva a cabo por una necesidad histórica que las conduciría de lo simple a lo complejo? En otras palabras itodas las sociedades han debido pasar por las mismas etapas en el desarrollo de sus cambios?

Los evolucionistas afirman que hay un esquema de evolución que debe cumplirse cronológicamente, debido a la unidad de la mente humana. Pero si bien es cierto que en algunos casos el desarrollo indepenaiente puede explicar muchos orígenes y cambios culturales, en cambio otros solo pueden atribuirse al difusionismo, o sea a la introducción de nuevos rasgos culturales, procedentes del exterior.

Si esto es así, en caso de haber sucedido por circunstancias históricas el proceso inverso, o sea que en vez de recibir un contacto exterior se expande la propia cultura,entonces el resultado habría sido también, para la escuela evolucionista, una ley de desarrollo.

Es muy fácil establecer históricamente lo que ha pasado, y luego afirmar que eso debió suceder así y no de otra manera, sin tener en cuenta que existen otros procesos inversos.

La teoría de la evolución, pués, no puede explicar suficientemente los cambios sociales, y ha sido reemplazada por el contacto o difusionismo y por el fucionalismo cultural. 


\section{II.- La sociedod}

Un problema de singular importancia, dentro de la Sociología de Cormejo, es el concepto de Sociedad y la determinación de los elementos que lo forman.

El Capítulo IV, titulado La Sociedad y el Progreso, está dedicado, en gran parte, a examinar esta idea, $y$ en verdad contiene fundamentos complementarios a los enunciados en el capítulo I de su obra.

En efecto, al comenzar la exposición de su sistema, afirma que la adaptación, el instinto de buscar el placer y huir del dolor y la lucha por la existencia, son las bases de la sociedad; que ella, como todos los organismos, no tiene otra finclidad que conseguir el equilibrio entre los factores internos y externos, esto es, que su trabajo consiste en un proceso de adaptación; que por eso, todas las costumbres, ceremonias e instituciones, desde las más humildes hasta las más elevadas, han de hallar la razón de su existencia en la fatalidad orgánica que tiene el individuo de adaptarse a las necesidades, ya del medio físico, ya del grupo en que vive, y de acaptarse, a su vez, el mismo grupo a las condiciones impuestas por otras agrupacions; (1) que la sociedad es un hecho natural, fruto de la reproducción orgónica, conservada por el mismo estímulo que mueve a toda actividad animal, por el instinto de buscar el placer y huir del dolor; que si el hombre se encontró en compañía de otros seres humanos desde su nacimiento habría necesitado de un esfuerzo doloroso para destruir una situación natural, afirmada por los sentimientos que crea el hábito (2); y que, por último, la vida en sociedad, cuya base es la diversidad de sexos, se conserva y progresa cuando es favorable a la lucha por la existencia, y la encontramos en aquellas especies que la necesitan para vivir, esto es, para conseguir el alimento o para defenderse, faltando en las que no recibirían de la asociación ninguna ventaja apreciable(3). Adaptación y lucha por la existencia son conceptos con que jugó la escuela del darwinismo social, distinguiéndose en ella, Novicow, Vaccaro, Malthus, Gumplowicz, Ratzenhofer, Sombart, Le Bon, Ward, y otros. La idea de Darwin sobre la selección natural fué desarrollada y eregida como la explicación final de cuanto acontece en la sociedad y de su estructura. Pero, un examen

\footnotetext{
(1) Cornejo, Sociología, et., p. 47.

(2) Ibid., p. 123.

(3) Ibid., p. 124.
} 
serio demuestra cuan equivocados estuvieron, si bien debemos reconocerles el mérito de haber llamado la atención sobre problemas que, indudablemente, tienen primerísima importancia en la estructuración de la Sociología.

Bien es verdad que Cornejo no se ć́lilió definitivamente a ia escuela darwinista, como lo hizo con la hipótesis de la evolución, sino que vinculó la teoría de la lucha con la solidaridad, pues afirma que al proceso de asimilación al medio debe agregarse el de resistencia al mismo, ya que las condiciones para que el agregado subsista es que las fuerzas externas no lo destruyan; y la fuerza de resistencia que se opone a la destrucción, es la solidaridad, fuerza evocada y condicionada por un proceso de reacción, y conservada y trasmitida por la herencia social, la tradición. (4).

Es indudable que advirtió los inconvenientes de la teoría darwinista pura y aminoró sus exageraciones con la idea de ayuda mutua o solidaridad.

La solidaridad, como elemento integrador de' la sociedad, fue tomada por Cornejo de la obra de Emilio Durhkeim, condicionando sus características con su especial orientación ecléctica. Para esto, no solamente modifica las ideas de Durkheim, sino las complementa con las teorías de Franklin E. Giddings, respecto a la conciencia de la especie.

La solidaridad, iajirma Cornejo, se deriva des la adaptación. Veamos como : la acción del medio físico impone necesidades semejantes, de las cuales arrancan las ideas comunes, fundamento de la solidaridad de Durkheim. Pero la solidaridad mecánica, según el sociológo francés, resulta del predominio de la similitud de las conciencias individuales, y se presenta en los grupos donde el psiquismo superior no se encuentra muy diferenciado, donde los hombres tienen igualdad de pensamiento, donde no hay gran división del trabajo y dende la unión del grupo se funda en la homogeniedad mental y moral de los individuos componentes, como sucede en las sociedades arcaicas o primitivas. En cambio, la solidaridad orgánica; según el mismo scciológo, se produce a consecuencia de la semejanza que introduce la división del trabajo, pues cuanto más se distinguen los miembros de un grupo, más indispensables son unos para otros, quedando al descubierto partes mayores de la conciencia individual y produciendo un mayor individualismo.

(4) Ibid., p. 142. 
Cornejo toma, para su sistema de sociología, la idea de la semejanza de las conciencias individuales, para de ellas hacer derivar la solidaridad (5) Y, ya hemos visto, estas ideas similares son productos de las necesidades, tamìién idénticas, que impone el medio a la $\alpha$ grupación primitiva, sea horda o clan; vale decir, son consecuencias del proceso de adaptación. Con esto tiene Cornejo un nexo lógico entre la hipótesis del darwinismo social y la idea de solidaridad de Durkheim.

Pero, del concepto de semejanza o similitud de las conciencias individuales, enunciado por Durlsheim, Cornejo, avanza hasta la teoría de la conciencia de la especie, fundamento de la sociología de Giddings.

Examinaré, brevemente, las ideas de Giddings respecto a la conciencia de la especie, antes de entrar a comentar las modificaciones introducidas a ellas por Cornejo. Para el sociológo estadounidense la asociación crea la conciencia de la especie, hecho subjetivo primordial del fenómeno social, y el desenvolvimiento de esa asociación se realizaría de la siguiente manera: (6).

a) La reunión o encuentro de dos personas, ocasiona la percepción de la desemejanza y de la semejanza, comenzando aquí el conocimiento de la especie.

b) La incertidumbre acerca del grado de semejanza, origina la comunicación, y si ella demuestra quee son demasiado semejantes para establecer el conflicto primario (conquista), se continúa con el conflicto secundario (contención) que puede ser de placer o de dolor.

c) El factor imitación se desenvuelve de individuo $a$ individuo. armonizando algunas prácticas y creando nuevos conflictos entre otras, antagonismo que encuentra finalmente su límite y término con el equilibrio y la tolerancia.

d) Por último, la tolerancia facilita la cooperación y la alianza.

Para Giddings, la conciencia de la especie es el factor que distingue el fenómeno social del no social y constituye la causa principal de la conducta colectiva. Este concepto, inspirado en la idea de la sim.

(5) Ibid., p. 146.

(6) Giddings, Principios, etc., p. 129. 
patía de Adam Smith, incluye las categorias de sentimiento y percepción, mediante las cuales la ascciación podría fundarse en la sćlo in. tuición de la semejanza o, a su vez, en el conocimiento cierto de ella, dando origen a la asociación deliberada.

Cornejo aprovechó la teoría de Giddings para vincularla con la de Durkheim sobre la conciencia colectiva, (tanto uno como otro afirman la existencia de ideas comunes de semejanza o diferencia) y fundar sobre ellas la conciencia de la especie o solidaridad mecánica, deduciendo que la conciencia de la especie podía muy bien reemplazar la conciencia colectiva del sociológo francés. De ahí su afirmación que la primera forma de la solidaridad dependa de los lazos consanguíneos que unen al cian primitivo y se funde en la conciencia de la especie. (7). Lar segunda forma de la solidaridad, en cambio, se originaría según Mariano H. Cornejo, en una fuerza diferente a las necesidades comunes e ideas iguales; en la tendencia a monopolizar los medics de subsistencia. Se añade así la fuerza que crea la disciplina política y se establece la solidaridad en su forma fundamental, la coercitiva. (8). En un tercer período, a los elementos de semejanza y coercitivos, sə une la cooperación industrial, producto de la división del trabajo.

En resumen, Cornejo propone tres elementos que van actuando para variar la naturaleza del vínculo de solidaridad : los sentimientos, la fuerza y los intereses comunes. (9) La sociedad - continúa- no puede existir si su solidaridad no cuenta con ese triple vínculo físico, orgánico y psíquico, nacido de la fuerza, del intercambio y de los sentimientos colectivós. La esolidaridad que forma dos grupos sociales, como elemento subjetivo descansa en el triple vínculo mecánico, orgánico, y psíquico, que nace de los procesos orgánico y social. (10).

Hemos examinado, así, cuales son los elementos que conforman una Sociedad, es decir aquellos vínculos que la mantienen unida y que evitan su dislocación. Ellos son, las diferentes formas de la solidaridad, fundada unas veces en la conciencia de la especie, otras en la fuerza Y, por último, en la división del trabajo. Veamos ahora lo que es una Sociedad, para Cornejo.

Tanto el organismo como la Sociedad constituyen un conjunto de seres vivos, pero su simple unión no forma siempre sociedades (11)

\footnotetext{
(7) Cornejo, Sociología, etc., p. 147

(8) Ibid., p. 148.

(9) Ibid., p. 149

(10) Ibid., p. 150

(11) Ibid., p. 186.
} 
pues, comenta Cornejo, no aceptamos que una selva sea una sociedad, porquie en ella no se encuentran los hechos sociales (12). De esto debemos deducir, porque no lo dice expresamente, que la Sociedad es la ruenión de seres vivas dentro de la cual se producen los hechos sociales.

¿Y qué es un hecho social? Cornejo nos contesta diciendo que son los modos de hacer, fijos o no, que impone el sentimiento de la solidaridad. Consecuente con las ideas anteriormente expuestas, corrige la definición dada poì Durkheim, cambiando la última parie, que se refiere a la coacción sobre el individuo, por el concepto cle solidaridad. En su definición, el signo característico es la relación entre la colectividad y el individuo, sentida o percibida por éste, vale decir, la intuiçión del vínculo colectivo es el elemento que conforma los hechos sociales (13). En oiros términos, un grupo de organismo forma una sociedad cuando en ellos existe un desarrollo psíquico suficiente para apreciar la unidad del grupo y la semejanza fundamental de sus miembros. De esta noción, conciencia de la especie para Cornejo, resultan dos fenómenos : $1^{\circ}$, el concurso simpático dentro del grupo, y $2^{\circ}$, la hostilidad con los elementos exteriores y diferentes. De ahí que si bien sólo los organismos de cierta superioridad, con exclusión total de los vegetales, pueden llegar hasta la vida social, ésta no es, en manera alguna, exclusiva del hombre. (14).

Pero en esas sociedades, privadas de lenguaje como medio de comunicación, las funciones sociales tienen radio tan estrecho que, repeticias invariablemente, se convierten en funciones orgánicas. (15). Las únicas sociedades, pues, que son Cobjeto delalsociología, son las sociedades humanas.

Sigamos examinando las ideas de. Cornejo respecto al concepto Sociedad. No todas las reuniones de hombres - afirma el sociológomerecen el nombre de Sociedades. Una reunión efímera o casual, los viajeros de un tren por ejemlo, no forman un grupo social. Es preciso que la reunión sea permanente, capaz de abrazar en el tiempo toda la evolución del individuo, para que la llamemos Sociedad. Ádemás de la permanencia, —continúa Cornejo-, es indispensable la universalidad del grupo social, pues una asociación literaria o comercial, aún permanente, no merecería el nombre Sociedad; es una corporación, par-

(12) Ibid., p. 187.

(13) Ibid., p. 187 y 189.

(14) Ibid., p. 189.

(15) Ibid., p. 190. 
te de un grupo social. Es preciso - vielve a repetir- que dentro del seno de la agrupación sea posible descrrollar, en cuanto a la sucesión y $a$ ia simultaneidad de funciones, todo el proceso de la vida individual. (16).

Ahora llegamos al concepto Socieciad valedero para Cornejo. Esa permanencia y esa generalidad - dice- solo pueden desarrollarse en las agrupaciones naturales en que aparece la especie humana, formadas por un proceso colectivo independiente de los fines individuales.

Para Cornejo, pues, el concepto Sociedad sólo puede atribuirse a los grupos naturales, mas no a las agrupaciones efímeras y temporales. Estos grupos naturales, en general, pueden ser de dos clases : los simples o domésticos, formados por las generaciones; y los compuestos o políticos, formados por la integración de un grupo de varias unidades simples. Las especies animales sociables sólo conocen la primera forma, y únicamente el hombre realiza la segunda. (17).

La sociedad está constituída por el grupo étnico, ya sea aislado en su condición primitiva de horda, ya integrado en agregados superiores. Así, Cornejo define la Sociedad como " el grupo natural de organismos dotados de conciencia de la especie". (18).

Estos grupos, crecen por la generación hasta cierto límite, después por la integración forzada de otros grupos mediante la conquista, y más tarde, en un grado de civilización superior, por la coordinación pacífica de varias entidades sociales pero en ninguno de estos casos pierden el carácter de agrupación espontánea, de forma natural en que se desenvuelve la vida humana.

En la actualidad, según Mariano $\mathrm{H}$. Cornejo, el grupo social se encontraría formado por las nacionalidades, y antes lo estuvo por la horda, la tribu y la ciudad. (19).

Llegamos, así, al final de la teoría de Mariano H. Cornejo, en lo que al concepto de Sociedad se refiere. Ja Sociedad, como hemos visto, sólo puede darse ahí donde exista un grupo natural. ¿Es enteramente cierta esta teoría?

Para llegara una conclusión valedera es preciso examinar detenidamente la realidad histórico-social, y para conocerla debe penetrarse en ella paulatinamente, desde el campo del ser físico.
(16) Ibid., p. 190.
(17) Ibid., p. 191.
(18) Ibid., p. 191
(19) Ibid., p. 191. 
Una primera distinción que debemos hacer se refiere a los fenćmenos físicos, que comprenden, los de la materia y energía, y sus transformaciones. Pero al lado de ellos existen también fenómenos de vida, ya sea vegetal o animal, cuya dinámica es completamente distinta a las anteriores.

Sobre estos dos reynos, el físico y el orgánico, es que se constituye la sociedad. Ella no puede existir sin su base material formada no solamente por la conformación geográfica y sus correlatos de clima, flora y fauna, sino por todo el cmbiente, natural o artificial, que condiciona el otro sustento de la sociabilidad, cual es la conformación demográfica o agrupamientos humanos. Dos pues, son los aspectos de tal base material : por un lado el geogróíico, y de otro el demótico. Las correlaciones entre estos dos fenómenos constituyen los primeros asientos de la asociación.

De ahí que esta base material se encuentre socializada, esto es, no escapa a la cicción del hombre, pues si bien actúan sobre él obligánclolo a adeptar diversas conductas, apropiadas a las circunstancias, en cambio recibe también la acción transformadora de la sociedad, a través de la técnica o de las costumbres o creencias colectivas.

$\mathrm{Si}$ seguimos avanzando en el análisis de la realidad histórico- social, después de hallar esta base material geográfico-demótica, debemos destacar al hombre como sujeto de estudio. Este, como unidad psicofísica, se encuentra a cargo de dos ciencias : la Antropología y la Psicología. Y es aquí, en el estudio del hombre, donde podemos advertir la frontera entre las ciencias espirituales y las naturales. La Psicofísica, precisamente, nació con el piopósito de establecer" con mayor precisión las relaciones efectivas del mundo corporal con el anímico. El centro de sus investigaciones lo constituye la relación funcional entre estímulo y sensación; estudia la dependencia de la vida espiritual con respecto a su base corporal, los límites dentro de los cuales se puede demostrar semejante dependencia y expone, a veces, los efectos de los cambios espirituales y corporales. (20).

Sin embargo, la Psicología no explica sino un aspecto parcial del hombre en sus generalidades espirituales como especie. El hombre como persona individual se conoce mediante la Autobiografía y la Biografía.

Ya tenemos entre manos el conocimiento del hombre; pero el individuo es un punto de cruce de las interaciones sociales, y puede rea-

(20) Dilthey, Introducción, etc., p. 47. 
lizar múltiples aclividades y desempeñar diferentes papeles en la sociedad. Este quehacer del hombre, su preocupación y padecer, en relación a los demás hombres y el tiempo, constituyen el historicismo. "La corriente del acontecer avanza en el mundo histórico social de un modo incontenible, porque nuestra existencia transcurre hacia su destrucción, hacia la muerte", afirma Freyer.

El tiempo es un concreto antes o después, es irreversible, y consis. te en la transformación del futuro en pasado a través de nuestro presente. I este tiempo está ligado nuestro existencia, ocupaciones y con. ducta. El historicismo es, pués, la vinculación de los acontecimientos humaros al tiempo primordial. (2l).

Ahora bien, los acontecimientos producidos por el quehacer de los hombres corresponde al dominio de la Crónica e Historia. La primera expone lc que todavía vive en el recuerdo de la generación actual. La segunda, abarca mayor cantidad de pasado y va penetrando más allá de la memoria de una generación. El historiador se encuentra en medio de escombros de cosas pasadas, de manifestaciones, de hechos, palabras, imágenes, sonidos, etc., producidos por hombres que han desaparecido. (22).

Pero, aparte del hombre y de su tiempo histórico, encontramos en la realidad otros órdenes distintos. P $P_{1}$ dvertimos, en primer lugar, el orden cultural, compuesto por sistemas de fines o valores. Estos sistemas de vida constituyen un modo de actividad que descansa en una parte constitutiva deja persona se desarrolla múltiplemente a partir de ella, satisface un fin en el todo de la sociedad, y se equipa con medios duraderos establecidos en el mundolexterior." (23) La religión, el arte, la moral, el lenguaje, el mito, el derecho, etc., son sistemas de cultura.

El arte, por ejemplo, descansa en una parte constitutiva de la persona : la fantasía, pero en sus creaciones se halla presente todo el mundo exterior e interior del individuo. A su vez, el mundo exterior le presta al sistema la capacidad de conservar y trasmitir de modo duradero los efectos de los individuos que tan rópidamente se disipan.

El individuo se encuentra dentro de una multitud de sistemas de cultura. Así, cuando un sabio escribe una obra, puede este hecho constituir a la vez : a) un enlace de verdades que conforma la ciencia; b) un importante proceso económico por la venta de los ejemplares; y c)

(21) Freyer, La Sociología, et., p. 106.

(22) Dilthey, Introducción, p. 50.

(23) Ibid., p. 57. 
un acto jurídico en cuanto se trate del cumplimiento de un contrato. El acto de escribir dicha obra forma parte de todos esos sistemas. (24).

La ciencia separa estos diversos sistemas que aparecen enlazados en la realidad social, y el individuo que se encuentra dentro del sistema lo considera como una realidad que se le enfrenta, que le ha de sobrevivir y que actúa sobre él.

Pero los sistemas de cultura pueden ser diferenciados desde dos puntos de vista : a) como normas; y b) como modos de vida de una comunidad. Y aquí encontramos la distinción entre las ciencias sociales particulares y la Antropología cultural o Historia de la cultura.

Si entendemos un sistema de cultura como una norma, esto es, en su finalidad, naturaleza y sentido íntimo, tendremos una ciencia social especial. Ellas, generalmente, afirman un deber ser, por ejemplo el $\mathrm{De}$ recho. En este sentido también, la Teología estudia el dogma religioso; la Estética el arte; la Jurisprudencia el derecho; la Etica la moral; y la Economía Política el valor económico.

Pero si en cambio estudiamos los diversos modos de vida jurídica de los pueblos, o las diversas formas cle la moral de las comunidades. entonces estamos haciendo Antropología cultural o Historia de la cultura.

La Etnología, en este orden, estudia las formas primitivas de cultura entre los pueblos salvajes $y$ en las capas inferiores de los pueblos cultos. (25).

Mac Iver ha estudiado a fondo el problema cle los órdenes social y cultural. Manifiesta que dentro del segundo, puede hacerse una distinción, separando la techología, que comprendéla diversidad de diapositivos, instrumentos y capacidades técnicas aplicadas al logro de las valoraciones y fines humanos. Por ejemplo, la técnica de las artes industriales, de la ingeniería, de los sistemas económicos de producción y distribución, de los sistemas militares, etc. (26).

En las sociedades más simples, añade Mac Iver, la distinción entre los órdenes cultural y tecnológico no se halla diferenciada. Todos los artefactos populares son a la vez expresiones de la cultura y de la tecnología, pues la primera está profundamente fundida en lo utilitario y vice versa. Lo ritual es tan importante como la artesanía en la construcción de una canoa, pues dentro de la organización de estas sociedades debe cumplirse con ciertos ritos al momento de cortar el ár-

(24) Ibid., p. 66.

(25) Kaj Birket Smith, Vida e historia de las culturas, etc., p. 27.

(26) Mac Iver, Causación, et., p. 226. 
bol y extraerle la corteza, ya que de otra manera traería grandes desgracias. La danza es, a la vez, un modo de recreo social y el medio de defenderse de los malos espíritus o de invocar los favorables.

Pero en el proceso que va de la sociedad simple a la compleja se van diśerenciando los órdenes cultural y tecnológico. La tecnología tiende a hacerse universal, los mismos instrumentos de transportes y comunicación ligan a toda la tierra, y en cambio los diferentes sistemas de valores distinguen unos grupos de otros. Cada grupo o cada sociedad tiene un estilo propio, un espíritu diferente, que emana de su especial orden cultural, de su singular manera de valorizar la vida y de concebir sus fines.

Para Mac Iver, uno de los mayores problemas de la sociedad contemporónea es el ajuste interno de estos dos órdenes : el cultural y el tecnológico. Mientras la técnica avanza, la cultura se mueve dentro de una diagonal torpe y oscilante, dando lugar a contínuos reajustes entre ambos órdenes de la realidad social. (27).

Los órdenes cultural y tecnológico también penetran en el orden social con mucha mayor intensidad que su base material. En efecto, los modelos sociales, las señas y signos colectivos y los símbolos sociales, que por su naturaleza corresponden al orden cultural, penetran profundamente en el orden ocial.

Los modelos sociales, que participan de los ordenes cultural y tecnológico, son de muy distintas clases : vestidos, técnicas industriales y agrícolas, reglas de educación y cortesía, fiestas nacionales y locales, educación, prácticas,ccostumbresi modós, eto.verso"

Son modelos técnicos los que guian el comportamiento de la vida cotidiana, como las recetas de cocina, y a toda la vida económica; y cuya validez depende exclusivamente de la repetición y del éxito de la operación. Por el contrario, son modelos culturales, aquellos que tienen un carácter estimativo o valorativo, como los procedentes de la moral, la religión, el derecho, el arte, etc. (28).

Asimismo, la esfera simbólica sirve de mediadora y facilita la asociación de las personas.

Sucede con frecuencia que los órdenes social y cultural no son diferenciados por muchos autores. Una razón por la cual esta distinción es fuente de dificultades es que todo lo que existe bajo condiciones sociales, dentro de la sociedad, puede ser llamado social, pues no hay

(27) Ibid., p. 242.

(28) Gurvitch, La vocación, etc., p. 59. 
ninguna configuración cultural o sistema de cultura que exista fuera de la sociedad, ya que los hombres crean esos valores o esos medios. no como seres aislados, sino ahí donde también hay establecidas relaciones sociales, o ahí donde existe el orden sacial. (29).

Hay en cambio, ciertos fenómenos que tienen derecho particular a ser llamados sociales. Tales son, por ejemplo, los modos bajo los cuales los seres humanos se agrupan o permanecen separados, las reglas para el intercambio entre los miembros del grupo, las actitudes que adoptan entre sí. Pero es verdad que este esquema de inter-relaciones está íntimamente entrelazado con su vida cultural, y así, por ejemplo, dos personas que forman una sociedad colectiva para explotar un negocio dan lugar a un orden social porque es unc reunión de personas, y también a un orden tecnológico porque aquella está destinada $\alpha$ ofrecer alguna utilidad. (30).

Con respecto a la religión que profesa una sociedad; el arte que surge de los grupos sociales: al derecho que se fragua y aplica en una colectividad; $\alpha$ los procesos económicos que se desenvuelven entre los hombres, el orden social no está contenido par la contextura objeliva de tales productos, ni por la lógica material de sus conexiones de sentido, ni por las relaciones que guardan entre sí: pero si está formaco por la manera como unos hombres se han relacionado o se.relacionan cuando profesan una religión, cultivan emociones estéticas, construyen y aplican el derecho, producen, cambian o consumen bienes. (31).

Ya podemos, pues, considerar lo que es la Sociedad. Ella existe ahí donde los individuos entran en acción reciproca, acción y reacción que se produce por "deterninados instintos eróticos, de reproducción, etc.) o para determinados fines (de defensa o ataque, de juego, adquisición, ayuda, enseñanza etc.) (32).

Iua acción recíproca hace que las personas se pongan en convivencia, en acción conjunta, en correlación de circunstancias, es decir que ejerzan influencias y que las reciban.

I.a Sociedad aparece, entonces, cucndo varios sujetos entran en interacción, es clecir, en influjo de acción recíproca. Una persona ejerce sobre mi una influencia, que me lleva a comportarme de cierta manera, conducta que refluye sobre aquella, quien a su vez reccciona de determinado modo, obrando de nuevo sobre mí; $Y$ así sucesivamente.

(29) Mac Iver, Causación, etc., p. 228.

(30) Ibid., p. 228.

(31) Recasens Siches, Wiesse, 23. 68.

(32) Simmel, Sociología, p. 13. 
(33) Las personas, pues, se miran unas a otras, tienen celos mutuos, se escriben cartas, comen juntos, conversan, discuten, se son simpáticas 0 antipáticas, se visten y arreglan unas para otras, etc., y todias estas $\mathrm{y}$ otras mil relaciones, momentáneas o duraderas, conscientes 0 inconscientes, efímeras o fugaces: nos ligan incesantemente unos con otros. (34).

Estas son las conexiones sociales que se producen entre los individuos psico-físicos y que ocasiona que la sociedad sea irrompible.

Tal conjunto de conexiones sociales dan origen a otra clase de asociación que es continuación de la primera : las agrupaciones sociales. En ellas, las energías recíprocas de los individuos se han cristalizado en unidades, y aparecen así Estados, sindicatos, sacerdocios, formas de familia, constituciones económicas, organizaciones militares, partidos políticos, gremios, municipios, sindicatos, clases sociales, etc., es decir, toda una serie de agrupamientos sociales.

Aparte de estos dos tipos de asociación : conexiones sociales y agrupaciones sociales, debemos considerar todavía las sociedades globales, formadas por la reunión vincular de agrupaciones sociales.

Según Gurvitch, estas sociedades globales se las puede clasificar de acuerdo con una enorme variedad de criterios, que en su mayoría se entrecruzan, como podrían ser, por ejemplo, el geográfico (sociedades occidental y oriental, americana, europea, etc.), histórico (sociedades arcaicas, civilizadas, pasadas, presentes, futuras), económico (sociedades capitalistas, no capitalistas), (etc. (35) a.S

Cuán lejos nos encontramosiahora de la teoría de los grupos natu rales adoptada por Cornejo. Es verdad que la Sociedad requiere de una base material proporcionada por la demografía, pero también es cierto que el sólo hecho de la reunión de personas no conforman una Sociedad. Cornejo advirtió ésto y afirmó que dentro de los grupos era la solidaridad el elemento que los mantenía en cohesión constante. Pero un análisis mucho más cuidadoso ha permitido descubrir en la base de toda sociedad una multitud de inter- relaciones, no únicamente solidarias, sino de dominación, subordinación, simpatía, alejamiento, acercamiento, etc. etc., que forman un tejido inter-mental que sustenta todas las superestructuras sociales.

La teoría de los grupos naturales ha sido superada, con exceso, por la Sociología.

(33) Ibid., p. 13.

(34) Ibid., p. 26.

(35) Gurvitch, La vocación, etc., p. 14 y 258. 


\section{$-361-$ \\ III._ La Teoría Oranicista}

Otro aspecto de la Sociología de IMariano H. Comejo, es la adaptación de la teoría organicista a los conceptos de Sociedad, evolución y progreso.

Ahora que ya tenemos una idea precisa de la Sociedad -afirma Cornejo- veamos si le conviene algunos de los elementos de los caracteres orgánicos, y en qué y con qué objeto puede decirse que la Socieclad es un organismo. (1).

A continuación expone las ideas de la teoría organicista, tomando los fundamenots de los mejores representantes de ella. Sin embargo, se da cuenta que esta teoría no reúne margen suficiente de garantía científica, y, muy apesar suyo, se ve obligado a formular reservas a las exageraciones de Schaeffle y Lillienfeld.

Ya desde Spencer comenzó a interpretarse la Sociedad con criterio bliológico, interpretación que adoptaron los citados P. Lillienfeld y A. Schaeffle, y continuaron su desarrollo J. Novicow, Renée Worms y Alfredo Fouillée. (2). La escuela afirma que la sociedad o grupo social es una clase especial de organismo, al igual de los organismos vivos; que ambos, el biológico y el social, ostentan iguales características en cuanto a constitución y funciones; y que, por consiguiente, las leyes de la Biología pueden ser aplicadas a la sociedad.

Cornejo es consecuente con tal interpretación, si bien la modera muy ostensiblemente. 'Si la Sociedad no es un organismo animal ni vegetal, afirma, forma en cambio un agregado superior, un todo en el que se encuentran los prindipios generales queodeterminan la conservación y el proceso de la vida en los organismos compuestos. Los fenómenos sociales tienen su base en la Biología, así como los biológicos tienen su base en la Química. (3).

En la Sociedad encuentra Cornejo el principio biológico del concurso de las partes desemejantes, que se manifiesta tanto en la recí-

(1) Cornejo, Sociología, etc., p. 192.

(2) Paul von Lilienfeld, "Gedanken über eine Social Wissenschaft der Zunkundft", Mitan, 1873-81; Albert Eberhard Friedrich Schaeffle, "Bau and Leben des sociales Korpers", Tubingan, 1875-78; Alfredo Fouillée, "La science sociale contemporaine", Paris; Jacques Novicow, "Teoría orgánica de la sociedad", 1899, en donde condensó sus ideas organicistas aparecidas en "Las luchas entre las sociedades humanas y sus fases sucesivas", París, 1883, y "Conciencia y voluntad sociales", 1896. También perteneció a la escuela organicista el sociólogo frances Renee Worms, quien tradujo a su idioma natal la obra de Cornejo y la recomendó en el prólogo de dicha edición.

(3) Cornejo, Sociología, etc., p. 193. 
proca dependencia del cerebro y estómago, en los seres vivientes, como en la Scciedad la tienen los que gobiernan con los que trabajan el campo. Estas ideas organicistas, han sido tomadas directamente de Fouillée; sólo que el sentido de su intervención en la sociedad es radicalmente diferente en el pensamiento de ambos sociológos.

Mieniras para Fouillér el organismo social es una realidad, para Cornejo se reduce a la simple aplicación de los principios biológicos a la Sociedad. De ahí que aclare su concepto diciendo que si bien exisisn analogías fundomentales entre la sociedad y los organismos, ello no significa que de manera alguna aquella sea un animal o un vegetal, sino que adopta la forma de un superorganismo especial y distinto de los demás, al cual puede aplicarse los principios generales de la Biología, como la selección, el equilibrio, y la adaptación. (4).

La idea del superorganismo, tomada de Spencer, le ha servido de base para circunscribir la influencia biológica sólo a la aplicación de los principios generales, descartando cualquier identidad que pudiera pretenderse entre los agregados humanos y los organismos vivos.

Pero no creyó excigerado, sin embargo, convenir con Fouillée que estando formada la sociecicid por seres que tienen vida, la reunión de elllos otorga también vitalidad a la sociedad que así se forme, ni que, como consecuencia de esto, exista una conciencia social que resuma el pensamiento de todos los hombres unidos por el lenguaje y demás medios de expresión.

La vinculación de los principios estrictamentesbiológicos con los fenómenos derivados de la vida misma, como la inteligencia, es el siguiente fundamento para que Cornejo se adhiera nuevamente a las ideas de Fouillée, referentes al concepto contractual del superorganismo. La sociedad, dice Cornejo, es una organización viviente que tiende, por la inteligencia de sus miembros, a convertirse en un organsmo consciente y convencional. (5) El organismo de Cornejo, es como se entiende, esencialmente contractual.

Sin embargo, así tratada, la teoría organicista ponía en peligro la unidad de todo el sistema sociológico que estaba empeñado en construír Mariano H. Cornejo, y tuvo por eso necesidad de vincular estas cuestiones fundamentales con la no menos esencial de sus ideas, la teoría de la evolución.

El principio biológico, dice, es de manifiesta utilidad para definir el progreso y sus condiciones, toda vez que el concepto de progreso es un

(4) Ibid., p. 201
(5) Ibid., p. 214 
concepto vitalista (6). Esta concepción biológica nos presenta el progreso - añade- como un desenvolvimiento de la organización por el antagonismo de las fuerzas, como una modificación de la estructura por la adaptación de las funciones, y como un movimiento interno y externo del orden que lo consolida, aumentando sus elementos y su flexibilidad.

La resistencia de un medio limitado crea la adaptación con sus dos procesos de asimilación y de reacción. Tanto una como otra significan modificación, pues quien se asimila modifica su estructura, y quien reacciona modifica el medio que lo hostiliza. Como el progreso es una forma de adaptación, su posibilidad y grado dependen de las condiciones que rodean a cada grupo, que son, por un lado, la energía del mismo, y por otro, la variedad del medio. En consecuencia, un grupo progresa cuando, en virtud del proceso de reacción inconsciente, resulta cada vez más independiente del medio. (7) Es evidente que en resumen, -concluyeel progreso es la forma que la evolución toma en las sociedades, pero, como el fin de la adaptación no es el mejoramiento sino la conservación de una sociedad, el progreso no es en manera alguna necesario, pues depende de las condiciones del medio y del agregado. Si aquel, después de haber sido favorable, tórnase en notoriamente adverso, se inicia un proceso de regresión. ( 8 ).

Organismo y progreso, son los extremos con que une la teoría de la evolución.

Comenzaré por criticar las ideas organicistas aplicadas a la Sociedad, para luego examinar el flaco problema del progreso.

El hecho que las leyes de la Biología sean pertinentes al hombre en cuanto ser biológico, no quiere decir quellas mismas leyes puedan explicar el origen y desarrollo de las Sociedades, pues con el mismo criterio, y advertimiento que las leyes de la física y de la química también se aplican a las plantas y animales,debería considera como seres del reino físico a quienes por necesidad deben colocarse dentro del reino orgánico. La aplicabilidad de algunas leyes a varios objetos no significa la identidad de naturaleza de todos ellos.

De igual manera, el hecho que la Sociedad esté formada por personas que se encuentran estructuradas por el principio de los organismos biológicos, no quiere decir que sea un organismo ni que participe de la naturaleza de esta clase de cosas. Todas las similitudes que han encontrado los sociológos organicistas, a partir de Spencer, no son sino
(6) Ibid., p. 217.
(7) Ibid., p. 105.
(8) Ibid., p. 225. 
analogías más o menos verbalistas, pero sin ninguna realidad óntica. La metáfora se generalizć como instrumento de interpretación, y se llegó a abusar de ella al quererla considerar como la expresión de realidades que se encuentran dentro del orden social

Sobre la base de metáforas no puede constituírse la ciencia.

Veamos ahora la idea del progreso. Ya desde la aparición de la obra de Comte la idea del progreso tomó asiento en la teoría sociológica. El filósofo francés definía ese concepto como la forma dinámica del orden, que se manifiesta, desde el punto de vista objetivo, como un control cada vez mayor del hombre sobre el medio, hipótesis que fue desarrollada posteriormente por Spencer como el cambio de estructura del crganismo social por aplicación de la ley general de evolución, pero con la característica de ser un proceso simplemente natural y genético, en el cuál para nada intervendría la voluntad humana. De esto concluye que el progreso no es un accidente, no una cosa que esté sujeta al poder humano, sino una bienhechora necesidad. (9).

Posteriormente, Lester F. Ward también introdujo en su sistema la idea del progreso, afirmando que la interacción vigorosa de dos fuerzas, el antagonismo, oposición y lucha, transforma aquellas en energía y ésta en poder, construyendo las estructuras políticas y sociales; y después de que están construídas, la misma influencia las transforma. Este proceso constituye el progreso. Pero el verdadero sentido del progreso en Ward se encuentra en su concepción de la mayor intervención del hombre en su propio avance. Desde el principio, afirma, ha habido obstáculos a la consecurcióne de los deseos (y su remoción en la causa íntima de todo progreso social: transforma el medio, modifica las estructuras sociales existentes y produce otra nuevas. (10) Por aplicación de su hipótesis sobre génesis y télesis sociales, afirma que el progreso en los períodos humanos primitivos fue genético, pero comienza a ser télico en los contemporáneos, debido al desenvolvimiento de la facultad intelectual.

Giddings, con sus ideas sobre la adaptación, contribuyó también eficazmente a afianzar la idea del progreso en la Sociología.

De todas estas influencias, Mariano H. Cornejo, guiado por las ideas de Fouillée dedujo que el concepto biológico en la Sociología era el único capaz de hacer inteligible el concepto del progreso, pues de otra manera él sería inexplicable.

(9) Spencer, "Progress", Essays, etc., p. 60.

(10) Ward, Outlines et., Cap. VIII. 
Como ya se ha visto, su tesis sobre el progreso participa no solamente de las ideas de Comte y Spencer, sino esencialmenete de las expuestas por Ward y Giddings.

Sin embargo, la idea del progreso ha sido dejada de lado en la Sociología, y, a mayor abundamiento, nunca llegó a ser un tema central en la ciencia de la sociedad.

El progreso ha estado siempre vinculado a su concepto contrario, el orden, y los sociólogos del siglo XIX, comenzando por Comte y siguiendo con Le Pay, Proudhom y otros, creyeron que todas las tensiones y conflictos que se observaban en la sociedad podían clasificarse dentro de estos dos extremos de una misma línea. La estática y la dinćmica sociales fueron dos capítulos de la Sociología, que se oponían contínuamente.

Pero lo que desde un punto de vista es orden, desde otro es desorden, y con razón Gurvitch hace rotar que el orden que los niños consideran en un juego, es desorden para las personas mayores; que, de igual modo, lo que es orden desde el punto de vista de una clase social es ciesorden descle el punto de vista de otra, etc. (11).

En verdad, la realidad social se caracteriza por un entrecruzamiento de tensiones con distintos grados de intensidad, que jamás dejan a la sociedad en reposo absoluto.

Por otra parte, el concepto progreso importa un juicio de valor, pues significa que un estudio social ha mejorado con respesto a otro, anterior o coexistente. I La cienciac sin embargo, no puede llegar a los juicios de valor sin dejar de perder su base de certeza. Qué criterios deberían establecerse para considerar que el desarrollo económico del libre cambio significa un progreso respecto al sistema económico que le precedió?, o que la familia consanguínea importa una etapa superada por la familia conyugal, vigente en la actualidad? Si las tablas de valores varían de una sociedad a otra, y de una filosofía a otra filosofía, no podemos contar con un sistema de valoración que nos proporcione una base firme en que apoyar nuestros juicios.

En consecuencia, la idea del progreso es esencialmente relativa y carece de sentido dentro de la Sociología. Las estructuras sociales cambian y se modifican, pero ello no quiere decir que él pueda explicar el sentido de dichos cambios.

La posición de Cornejo, sin embargo, estuvo acorde con el estado de los estudios sociales contemporáneos a su formación doctrinaria.

(11) Gurvitch, La vocación actual, etc., p. 25. 


\section{IV.- Los Factores y Productos Sociales.}

El verdadero aporte de Mariano $H$. Cornejo a la ciencia de la sociedad, se encuentra en su magnífico estudio de los factores y productos sociales. En él demuestra la profunda erudición con que procedía, pues cita a los más calificados autores de cada uno de los temas que comenta, constituyendo el capítulo, unas de las mejores divulgaciones del estado de las investigaciones sociales a fines del siglo XIX.

Cornejo sintetiza y armoniza una serie de escuelas $y$ tendencias doctrinarias que hasta entonces habían sido inconciliables, tomando de cada una las afirmaciones universales que podían mantenerse como ciertas dentro de cualquier tipo de Sociología, y limando las oposiciones de unas con las otras.

En efecto, no puede encontrarse mayor discrepancia entre la escuela de Wundt y la preconizada por Spencer y Ward, que, sin embargo, lienan casi todo el esquema de Cornejo. Mientras la útima es naturalista, la primera se orienta hacia el psicologismo, pues Wudt no afirmó la sucesión de etapas culturales, como lo hacía la escuela clásica, sino la existencia de un desarrollo psicológico, mas no histórico. En cambio, tanto Spencer como Ward preconizan la transformación de las fuerzas físicas en socialest que deben participar de las mismas leyes que sus progenitoras. Naturalismo y psicologismo se encuentran y concilian dentro de la Sociología de Comejo, delfal 'suerte que, en vez de excluirse y oponerse, se unen y complementan. Es por esta razón que su sistema debe clasificarse como sintético y, a la vez, de transacción.

La idea de fuerzas sociales como factores de evolución, ha sido adoptada de las sociologías de Spencer y Ward, quienes, como se ha visto anteriormente, afirman la existencia de fuerzas físicas que, transformadas, dan origen a cuanto sucede dentro de la sociedad. Sobre la base que el organismo social está formado por los grupos étnicos naturales, Cornejo toma la idea de las fuerzas, desde el punto de vista causalista, para explicar el desarrollo de las instituciones y creencias. Solamente que distingue entre la causa y el efecto, esto es, entre los factores y los productos sociales. Cree que ambos son elementos esenciales dentro de la estructuración de la sociedad, pero que unos son primarios por su generalidad, concurrente con la generalidad del agregado mismo, y que por su acción permanente y contínua deben ser re- 
conocidos, especialmente, como factores. (1) Tanto los factores como los productos son, para Cornejo, fenómenos sociales, sólo que los primeros se consideran en relación con sus efectos, y los segundos con sus causas. (2).

Esta es, también, la distinción que le sirve para fijar los límites de Ia Sociclogía, pues cree que ella debe ocuparse del estudio de los factores, dejando los productos para las ciencias sociales especiales. (3).

Sin embargo, los productos llamados primarios, es decir aquellos que reunen las características de generalidad y permanencia, también los considera como factores o causas de cambios en la sociedad.

Son productos primarios fundamentales, (adaptación hecha de Wundt), el lenguaje, el mito y la moral.

Consecuencia del concepto de fuerzas que actúan dentro de la sociedad, es la estructuración de una Sociología positiva y al estilo de las ciencias naturales, cuyas raíces $\mathrm{y}$ efectos, dentro del pensamiento de Cornejo, ya se ha puesto de manifiesto en los anteriores capítulos.

Cornejo, además, adopta la división de Spencer para los factores sociales, considerándolos internos y extemos. En efecto, el sociólogo inglés, como ya también hemos visto, cree que los fenómenos sociales resultan de la acción combinada de elementos extemos, como los cambios geológicos, el clima, la temperatura, las condiciones higrométicas, la fertilidad del suelo, flora, fauna, etc.; y de elementos internos, tales como los caracteres físicos, morales e intelectuales de los individuos que componen una sociedad. (4).

Cornejo, siguiendo igual directiva, divide a sus factores, también, en internos y extemos, agregando a los segundos, además del principio biológico de herencia, propiciado por la escuela darwinista, los de raza y población, cuyo estudio estaba en boga por entonces; clasificándolos a todos dentro del rubro de factores individuales. Aparte de éstos, considera Cornejo otro grupo, mucho más importante, y en donde desenvuelve la idea fundamental de su sistema, o sea los factores colectivos, formados por los procesos generales inconscientes y los voluntarios. Los factores externos se reducen $\alpha$ la influencia del medio sobre la cultura.

(1) Cornejo, Sociología, etc., p. 234.

(2) Ibid., p. 233.

(3) Ibid., p. 234

(4) Ibid., p. 234. 
El cuadro general de los factores, sería el siguiente:

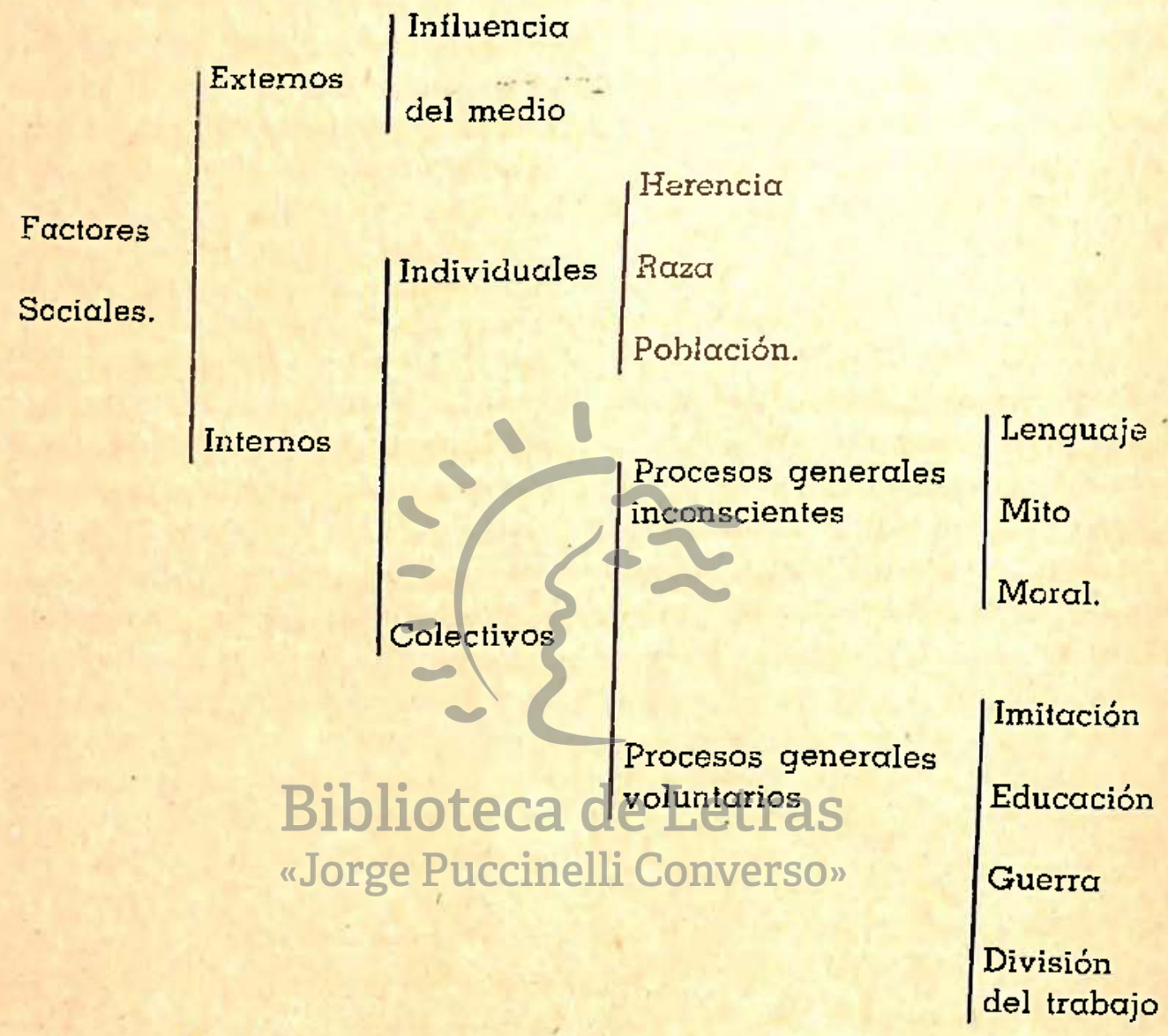

Cuando Cornejo se ocupa de los factores externos, recapítula Jas investigaciones practicadas por Buckle, Demalins y Ratzel, reservándose la explicación última sobre la forma como el medio físico y sus elementos : el clima, la temperatura, la posición geográfica y la naturaleza de cada región, ejercen influencia sobre la sociedad.

Las tendencias fundamentales de las especies, afirma el sociólogo, Y las peculiares aptitudes de sus variedades étnicas, obedecen a la influencia inmediata a lejana del medio físico, puesto que Ios efectos del clima son innegables en los organismos y, acumulados de generación 
en generación, producen importantes consecuencias sociales. La radiación solar es fuente de la vida y como la civilización no es sino una de sus formas, se desarrolla sólo en las regiones que reciben cantidad suficiente de luz y calor. Consecuentemente, ahí donde esas fuerzas son exígüas también la evolución social es insignificante. (5).

Igualmente considera Cornejo que las variaciones de la temperatura influyen en la densidad de la población y vigor de la raza, y por lo tonto en los fenómenos sociales; y que las regiones aburidantes en agua atraen los grupos humanos, sirviéndoles de medios de comunicación, en forma que la civilización sería una planta acuática. (6). Por los mismos motivos, afirma, la posición geográfica puede producir el aislamiento y su consecuencia, el estancamiento de la civilización.

Asegura, también, que el medio determina la naturaleza del trabajo, pues el pastoreo es efecto directo de aquel, y da lugar a la vida nómade, a la autoridad fundada en el concepto biológico de la descendencia, a la familia patriarcal y al culto a los antepasados. La selva resultaría opuesta a la civilizarión.

Nada que no se encuentre en los autores antes citados puede hallarse en el capítulo dedicado por Cornejo al estudio de los factores externos de la sociedad.

La influencia del medio sobre la cultura, sin embargo, no puede interpretarse como un determinación de ésta, pues si bien es cierto que toda la vida económica y aún mental del hombre está limitada por los recursos del país que habita. sime embargo el poder del medio físico sólo se refiere a las modificaciones de una forma cultural preexistente pero no puede ser considerado, por si mismo, creador.

Franz Boas afirma que un suelo fértil puede inducir a un pueblo agricola, cuyo número aumente rápidamente, a mejorar su técnica, pero no que esa pudiera ser la causa de la invención de la agricultura, ya que por rico que un país sea en minerales, ello no crea técnicas, (cultura), para la manipulación de los metales, así como por rico que sea en animales susceptibles de domesticación, no se llegará a la ganadería si un pueblo es enteramente ajeno a los usos de los animales domésticos. (7).

Todo esto demuestra el hecho que un mismo medio no produce una misma cultura, Boas cree que la influencia del medio físico sobre la cultura sólo es efectiva cuando aquella recae sobre la mentalidad, de tal

(5) Ibid., p. 281.

(6) Ibid., p. 284.

(7) Franz Boas, Cuestiones fundamentales, etc., Cap. X. 
manera que las características de la mente deben intervenir en las formas determinantes de la actividad social. Esta influencia, sin embargo, es bastante relativa, pues la mentalidad de un grupo social no depende exclusivamente de los factores físicos, sino de todo el complejo cultural mismo, de manera que hay mutua interferencia entre dichos elementos.

Lo esencial en la determinación de la cultura no es, en consecuencia, la influencia del medio físico, no únicamente porque éste sea incapaz de creación, sino porque aún en circunscripciones efectivamente prom:soras, como la abundancia de focas en ciertas zonas de vida esquimal, no son aprovechadas por la existencias de tabús que, indudablemente, no tienen ninguna relación con el medio gecgráíico.

Pero, por otra parte, la influencia del medio en las relaciones sociales y en la configuración de las instituciones es todavía mucho más problemática, toda vez que la Sociología no se ocupa concretamente del estudio de la cultura de un pueblo determinado, sino de los modos de asociación, como sucede con la guerra, la imitación o el suicidio. Modos en los que bastante difícil es encontrar alguna influencia de los factores f́sicos, si se tiene en consideración de las vinculaciones individuales que formon lo sociedad tienen una naturaleza esencialmente psíquica.

Además, se ha demostrado fácticamente que una serie de fenómenos no tienen ninguna vinculación con los factores geográficos. Por ejemplo, las diferencias de alimentación de las diversas clases sociales, dentro de unarmisma sociedade ho puedeeimputarse a las condiciones geográficas, y lo mismo puede decirse de las iendencias de los hábitos aimenticios en determinados países con relación a otros que tienen similares condiciones en la geografía. (8).

Es difícil convenir con los geógráos que el simple conocimiento de las condiciones geográficas de cierto territorio, puede darnos la pauta necesaria para predecir el carácter de las industrias o de las principales actividades económicas de una población, pues las condiciones de las estepas de Rusia $y$ de las praderas americanas son similares en muchos aspectos, y sin embargo las actividades económicas de la población nómade y semi-nómade de las estepas rusas son diferentes a las de la población de las praderas americanas. (9).

La intervención de otros elementos no geográficos, como los conocimientos agrícolas, la energía humana, el cuidado, la expansión del

(8) Sorokin, Teorías, etc., p. 120.

(9) Ibid., p. 124 
comercio, han estado limitando y neutralizando en medida considerable los efectos de las influencias geográficas en cuanio, por ejemplo, a la cantidad y calidad de las cosechas. (10).

Es evidente que no puede negarse la influencia del medio, pero sólo en alguons aspectos y muy morigerado por la acción de otros elementos no geográficos.

Los factores individuales, dentro del sistema de Cornejo, son la herencia, la raza y la población.

Al tratar de la herencia, aprovecha las investigaciones de Darwin, Ribot, Galton, Weisman, Jaeger, Delage y Datec, siempre otorgando a su divulgación el acento característico de la claridad y sencillez de su estilo.

Afirma Cornejo que la herencia conserva o transmite diferencias de ternperamento que dan su base al carácter, siendo así uno de los factores que contribuyen a diferenciar los tipos sociales. Las clases, sin embargo, no han logracio vincularse a la herencia, según piensa el notable sociólogo peruano.

De conformidad con la opinión de Jacoby, asegura Comejo que la herencia es una fuerza democrática que destruye las aristocracias y, siguiendo a Fouillée, que la influencia social más notable de la herenciar es la formación de temperamentos y caracteres.

Los tipos sociales son, para Cornejo, la masa, dispuesta a dejarse conducir, y la minoría dirigente. Las sociedades salen del estado salvaje, en que sólo poseen instinto pero nointeligenciascolectiva, hasta que logra diferenciarse una minoría capaz de sentir y pensar un ideal, fundado primero en el pasado, luego en la acción, y por último, en el porvenir.

La iegla es, propone Cornejo, que las castas fundadas en la herencia están condenadas a la degeneración, prosperando solo aquellas que se reclutan por selección libre de los tipos sociales, como por ejemplo, la. Iglesia, que ha huído de ella mediante el celibato, sólo que éste privaría, a la población del porvenir, el concurso de individualidades escogidas.

Examinando la tesis de Cornejo, es preciso aclarar que la influencia de la herencia en la sociedad sólo sería aceptable si las tendencias innatas, corporales, y mentales de un pueblo, se reflejaran en sus costumbres, esto es, que a las peculiaridades corporales hereditarias le acompañaren rasgos mentales también hereditarios, como una mayor o menor inclinación al valor, energía, capacidad para el pensamiento

(10) Ibid., p. 182. 
abstracto, ingenio mecánico, tendencias musicales o estéticas, reacciones rápidas, habilidad de concentración, facilidad de expresión, etc.; pero en cada caso particular es difícil, si no imposible, establecer mediante una comprobación incontrovertible que la herencia sea la causa específica de tales realizaciones o de tal o cual grado de costumbres. (11).

Por otra parte, ¿sería posible encontrar la influencia de la herencia en las formaciones de los regímenes despóticos o democráticos? ¿Podríamos hallar la determinación de los actos de subordinación o dominación, coacción, etc., en las funciones biológicas de la herencia

Además, en la formación de las estomentos sociales, lo esencial no es su limitación por medio de la herencia, sino la potencia de una tradición que sobreviva a la extinción de las generaciones viejas y continúe llevando, por su vía, a nuevos hombres, de tal suerte que en lugar de la herencia en sentido físico aparezca la tradición histórica. En un sentido biclógico puro, todo estamento dominante se extingue, pero lo que verdaderamente disuelye las ordenaciones estamentales no es la desaparición de la nobleza como estirpe, sino cle su actitud, de su tipo, de sus aptitudes políticas y de su tradición espiritual, de donde la disolución de la conexión espiritual del estamento, su socavamiento, descrédito $\mathrm{y}$ destrucción ideológica, se convierte en el fin natural de la lucha de los movimientos democráticos. (12).

La influencia de la herencia, en consecuencia, ha quedado muy alejada de los principios verdaderamente-sociológicos.

El segundo facton in dividual deelą exposición de Cornejo, es la raza.

El verdadero problema que interesc a la Sociología, expresa el autor, es el referente a la psicología de las razas y psicología de los pueblos.

El primero no ha podido ser comprobado ni estudiado hasta la fecha, pues la única verdad deducida es la imposibilidad de determinar no sólo la psicología de las razas, sino las mismas razas que han entrado en la composición de los pueblos modernos. La psicología de los pueblos, en cambio, no obstante las enormes dificultades que también presenta su estudio, se encuentra mucho más avanzada, según Cornejo, en su investigaciones.

Sería imposible negar, afirma, que los pueblos comprendidos en un mismo período histórico se distinguen por ciertos caracteres, pues es evidente que las influencias del medio físico y las mismas condicio-

(11) Kroeber. Antropología, etc., p. 195.

(12) Freyer, La Sociología, etc., p. 204. 
nes sociales acumuladas por muchas generaciones, acaban por constituir maneras especiales de senirir y de pensar. Sin embargo, cree que un juicio de esia clase, para que retrate la realidad siquiera en parte, tjene que reducirse no sólo a un pueblo determinado y período histórịco fijo, sino establecer una comprobación con una época también concreta de otros pueblos. (13).

Piensa Cornejo que la psicología de un pueblo ha de deducirse teniendo en considercición todos los factores, $\underline{Y}$ en especial los factores scciales e históricos, pues el que vive en una socieded al fin concluye ๔similándose a sus ideas, sentimientos y prejaicios.

En este punto so apoyc Cornejo en los trabajos de Lazarus y Stenintlial, quienes por prinaera vez, en Alemania, acometieron la tarea à determinar la psicología de los pueblos a base de los uses y costumbres como expresiones de uniformidades subyacentes del carácter popular. Sin embargo, el que asumió la dirección definitiva de estos estuclics fue Guillermo Wudt, en su monumental obra : "Volkerpsichologie".

Cornejo afirma que cada vez se háce más difícil determinar la psicologic de un pueblo, debido especialmente al cumento del cosmopolitismo. La raza, desde el punto do vista psíquico, concluye, es sólo un factor lejano al lado de los múltiples e inmediatos que determinon la acción, en un momento dedo. (14).

Al estudio de la psicología de los pueblos ha sucedido una nueva disciplina que se ocupejido 18 psicologid social - la conducta humana dentro de una situación, y de las reacciones colectivas a estímulos conálogos complementarios. (15).

El problema principal de la psicologia social consiste en descubrir y anclizar los métodos objetivos mediante los cuales el individuo inlegra su personalidad, $y$ las fuentes de donde recibe los estímulos que determinan las respuestes ccuscntes de la integración, sociclizando al individuo $\mathrm{y}$ adaptándolo al mundo cque lo rodec.

Bernard, tratadista coniempotáneo de los problemas de la psicología social, cree que la fuentes $\mathrm{y}$ estímulos de la socialización del indivíduo son su medio social, y los métodos objetivos empleados para ello, Ia sugestión y la imitación. Sin embargo, el profesor Bemard no otorga a estos procedimientos al carácter de entidades no derivadas, como es frecuente entre los sociólogos que pertenecen a la escuela de Tarde, si-

(13) Cornejo, Sociologia, etc., p. 275.

(14) Ibid., p. 277.

(15) Bernard, Psicología social, etc., p. 97. 
no los considera términos objetivos o conceptuales empleados para describir las formas que toma el condicionamiento de las reacciones del individuo a los estímulos de su medio social.

Todos los aspectos del medio social, afirma, ofrecen estímulos para el condicionamiento de las respuestas, especialmente de las respuestas por sugestión, pero la fuente principal de estímulos sería por supuesto, el medio psicológico social. El condicionamiento de las respuestas mediante la imitación tiene siempre que producirse por la conducta de alguna persona concreta o por los símbolos de esa conducta qure sirve como estímulo, puesto que no imitamos instituciones, aunque podemos imitar la conducta de las personas en las instituciones.

Para Bernard, la sugestión existe cuando cualquier resolución relativamente irreflexiva e inmediata se produce respecto a un estímulo mediante mecanismos de conducta que ya han sido preparados. Una respuesta sugerida se hallaría generalmente condicionada a un símbolo o estímulo iniciador, y no a la percepción de una situación total.

La imitación, en cambio, consiste en hacer lo mismo que otra persona porque la percepción de su conducta provoca, en quien imita, reacciones iguales o análogas a las que sirven de estímulo.

La psicología social no invade el campo de la Sociología, pero en cambio puede arrojar innumerables luces sobre una serie de problemas que el investigador de la sociedad no se encuentra capacitado suficientemente para "explicarlos.CEngranCpasoeque"ha dado la psicología social consiste en su total desvinculación del concepto raza, reemplazándolo por el funcionalismo del individuo y su medio social, toda vez que no reaccionan psicológicamente igual un niño de la cuidad que otro del campo, dentro de una misma raza o puebo, independientemente de sus caracteres biológicos, pero sí fundamentalmente en relación con la socialización que hubieran podido conseguir mediante la acción de la imitación y sugestión.

Consecuentemente, la obra de Cornejo, aunque de acuerdo con el estado de los estudios sociales de la épcca en que se gestó, no puede en la actualidad subsistir como principio explicativo ante los avances de las investigaciones de la psicología social.

El tercer factor individual, en el sistema sociológico de Cornejo, es la población. La propagación de la especie humana, afirma, está vinculada a los factores físicos de alimentación y clima, y como el hombre vive en sociedad, que ejerce una constante influencia no sólo sobre la 
actividad individual sino támbién sobre el medio físico, resulta que entre éste y la población se interponen los factores sociales. (16).

De este modo, la población recibiría influencias principalmente del aspecto colectivo de los factores sociales, siendo así que ella misma es considerada por Cornejo como formando parte de las fuerzas sociales esenciales.

Cuando aborda el estudio de la población, se ocupa del número de individuos y de la forma como se distribuyen. El aumento de la población depende, para él, del mejoramiento de las condiciones de vida, con sus límites derivados del alcoholismo, la alimentación, el retardo en los matrimonios, la resistericia a dividir la fortuna, el deseo de no cuidar a los niños, y la prostitución.

Aparte de las condiciones de vida, también considera factor esencial en el aumento de la población o en su disminución, los movimientos migratorios, a los que clasifica en tres categorías : 1.- Desplazamiento total de pueblos y tribus, que obedecen a causas económicas. 2.Desplazamientos individuales o de pequeños grupos armados para la conquista, enviados por el grupo principal, o de colonización, que obe: decen a causas políticas, esencialmente. 3.- Emigración individual que obedece a influencias sociales, como la búsqueda de una sociedad que ofrezca mayores garanías, medios de trabajo o placeres. Como efectos de la colonización, señala Cornejo la decadencia de una alta civilización cuando se produce el contacto con pueblos primitivos, seguida de la despoblación debido, sobre todo eal cambio de las condiciones de vida y a la destrucción de la constitución social.

Otro aspecto del problema de la población es, según el sociólogo, la inmigración de los campos a las ciudades por causas económicas y sociales. La ciudad atraería porque ofrece mayor variedad de carreras, más demanda de trabajo y mayores oportunidades de ascenso so. cial.

El segundo aspecto del problema de la población es la forma como se reparte o se encuentra establecida, a tenor del pensamiento de Cornejo. Hay cuatro formas - afirma- como la población se estabiliza : la hacienda, el caserío, la aldea y la ciudad. La hacienda sería el establecimiento individual de un agricultor; el caserío y la aldea, un grupo de habitaciones de familia; y la ciudad, un centro de habitación considerable.

La aldea sería la forma natural en que las comunidades se establecen conservando las vinculaciones de la tribu. En cambio el origen

(16) Cornejo, Sociología, etc., p. 382. 
primario de la ciudad estaría en la fortaleza, en la elección de un sitio para defenderse. El grupo que lograra crear la ciudad echaría las bases de un imperio, porque la ciudaã así constituída era la expresión del Estudo mismo. En camíio, la ciudad moderna habría tomado otra. dirección, dominando en ella los factores económicos. Por último, la multiplicación de las ciudades habría producido su diferenciación en comerciales, industriales y literarias. (17).

Para exponer la teoría de la pobiación como factor o fuerza social, se ha valido Cornejo de las investigaciones cle Jacoby, Schmoller y Ihering, que esencialmente se rerieren a los problemas demcgráficos $ə$ históricos.

De Paul Jacoby ha tomado las ideas sobre las limitaciones al aumento de la población aparecidas en su obra "Etudes su la sélection dans sea rapports avec l'heredité chez l'homme", en 1881. De Schmoller recibió los resultados de sus estudios sobre el desarrollo económico de la población, a través de su libro "Grundriss der allgemeinen Vollsswirtschaftslehre"; y de thering los principios enunciados sobre el origen posible de la ciudad, expuesto en su tratado "Prehistoria de los Indoeuropeos".

Afirma Cornejo, como principal efecto de la distribución de la población, siguiendo a Spencer, que en el campo el hombre de consideración tiene una superioridad especial, independiente a su valor propio, debido a su aislamiento; mientras que en la ciudad esas cualidades pierden las nueve décimas partes de su prestigio por la comparación con otros muchos Gindividuos. Äquío encuentra la tendencias aristocráticas del campo y las igualitarias de la ciudad. (18).

Al explicar la acción del tercer factor individual, Cornejo se limita, sin embargo, sólo a hacer una descripción de la población en cuantc a las formas que es posible adopte o haya adoptado a través de los tiempos, deduciendo una que otra consecuencia de aquellas ,como por ejemplo la destrucción de una alta civilización por el choque con otra más atrazada, o el efecto de la ciudad y el campo en la individualización de las personas.

La población, tal como la concibe Cornejo, carece de significado para la Sociología, porque resultaría una simple descriptiva de un aspecto más o menos esencial de la sociedad. Lo verdaderamente importante en el estudio de una población, no es la evolución más o menos comprobada de sus diferentes estadios, ni la forma como se distribuye

(17) Ibid., p. 413

(18) Ibid., p. 413. 
en todo el mundo, sino los efectos que puede ocasionar su mayor o menor volumen, es decir, el número de habitantes es la clave para la explicación de una serie de fenómenos, cuya naturaleza sólo es posible calificarla con ayuda de su función.

En el estudio de la población es necesario establecer correlaciones entre el tamaño y densidad de la población con los procesos vitales (promedios de natalidad y mortalidad); la migración y movimien. tos de población; la guerra; los fenómenos económicos; las formas de propiedad y posesión; la prosperidad y depresión económicas; las formas de organización social; la estratificación y segregación sociales; las invenciones y los hombres de genio; las costumbres y las usanzas, los fenómenos ideológicos, etc. Sólo comprobando estas correlaciones entre el fenómeno social de la poblacićn y su densidad con otros fenómenos sociales puede determinarse un efectivo funcionalismo de lo que Cornejo denomina factor población.

Nos toca ahora el examen de los factores colectivos o verdaderamente sociales.

La vida social, afirma Cornejo, tiene una parte en que predomina el proceso espontóneo, por lo general inconsciente, y otra en que se destaca un proceso en su mayor parte consciente y voluntario. (19).

Los procesos generales espontóneos o inconscientes, estan formados por tres productos primarios: lenguaje, mito y moral. Son productos porque se derivan de la inteligencia, el sentimiento y la voluntad colectivos; pero a la véz son factores porque dado el carácter primario de ellos, constituyeil asimismo causas permanentes del desenvolvimiento contínuo del álmá colectîa.inelli Converso" *

Cornejo reproduce íntegramente la tesis de Wundt, no solamente al tratar de los factores sociales, sino también en todo el segundo tomo de su obra, dedicado a divulgar el sistema psiciologístico del pensador alemán, pero refiriéndola siempre a las ideas de otros investigadores de la cultura.

Consecuente con esta influencia, el sociólogo peruano se adLiere fervientemente a la teoría de la conciencia colectiva, como correlación de las conciencias individuales, (20), teoría que ha sido motivo de fuertes críticas a raíz de su incorporación a la Sociología por Emile Durkhieim, quien hizo de dicho concepto el fundamento principal de su sistema, tanto en lo referenie al método sociológico, como en sus ideas scbre la solidaridad, suciología jurídica, religiosa, teoría del suicidio e

(19) Ibid., p. 237.

(20) Ibid., p. 241. 
interpretación del totem y el mana. En la actualidad ha áesarrollado igual concepto, con evidente superioridad, el sociológo Georges Gurvich. (21).

No obstante la poderosa influencia recibida de Durkheim, en lo referente al hecho social y la solidaridad, sus ideas sobre la conciencia coleciiva las tomó Cornejo de la psicología social de Wundt, juntamente con los conceptos primcrios del lenguaje, mito y moral.

Los productos generales voluntarios adquieren, dentro de su Sociología, especial importancia, porque les correspondería organizar la sociedad en sus formas externas, perfeccionando los productos primarios y creando otros nuevos.

El sincretismo de Cornejo se manif́iesta en toda su pureza cuando se examina esta parte, porque en ella póne en juego la asimilación de casi todas las doctrinas que hasta entonces había utilizado, unificándolas en una estructura fundamental que serviría de explicación primaria para todos los exiremos del sistema.

En la sociedad, afirma, hay dos formas esenciales, fruto del instinto de igualdad, que tienden a la homogenización social : la imitación y la educación; y hay otros dos procesos, frutos del instinto de libertad, que conducen a la diferenciación : la guerra y la división del irabajo.

Ambas corrientes, continúa, obedecen a dos grandes instintos humanos : el instinto individual de la libertad, que se deriva del instinto de conservación : Yel instintoespecífico de la igualdad que se deriva del instinto de reproducción.

Todos estos factores, termina el sociológo, afirman la solidaridad, pues la imitación y la educación favorece el tesoro de las ideas comunes; la guerra presta la cohesión llamada autoritaria; y la división del trabajo la afinidad económica que se traduce en el cambio recíproco de valores sociales.

En este sentido, todo el sistema de Cornejo se funda en la solidaridad, íntegramente tomada de Durkheim, como se ha visto anteriormente. La solidaridad es, pues, el punto central donde se cruzan y confluyen las diversas tendencias que integran su Sociología, principio que le sirve de complemento $\mathrm{y}$ vinculación $a$ efecto de formar un sistema coherente y metódico, capaz de contener la multitud de orientaciones que hasta entonces había tomado la ciencia social, pero complementándose unas a las otras, antes que excluyéndose por implicantes y contradictorias.

(21) Gurvitch, Las formas de la sociabilidad. Buenos Aires, 1941. 
Junto a la solidaridad, Cornejo hace jugar otra idea central, adquirida de su afición por la teoría de la evolución, cual es el principio de integración y diferenciación, con sus correlatos; homogeneidad y heterogeneidad. De esta manera Spencer se enlaza con Durkheim y forman una continuidad doctrinaria capaz de explicar, dentro del propósito de Cornejo, la naturaleza propia de la socialización.

Ia imitación y la educación, mediante los procedimientos de sus causaciones originarían una igualdad v. homogenización de lo heterogéneo, esto es, el cumplimiento de una de las leyes principales de la evolución. Esta igualdad no hace sino favorecer las ideas comunes que, según Durkheim, son la base de la solidaridad mecánica. Es decir, otra vez se llega al punto básico de toda sociedad : la solidaridad.

Por otra parte, la guerra y la división del trabajo originarían la dominación mediante el empleo de la fuerza, y crearían diferenciaciones recíprocas y complementarias, las mismas que darían lugar a la segunda forma de solidaridad propuesta por Durkheim : la solidaridad mecánica. Nuevamente, pues, se llega al punto de partida de la teoría de Cornejo, a través del camino trazado por Spencer.

Un sólo propósito y finalidad tendría la acción de los procesos generales voluntarios : la facilitación y robustecimiento de la solidaridad, aspecto esencial de toda sociedad y centro de cualquier actividad humana.

Para el Sociológo, materia de este comentario, el estudio de los factores sociales corresponde a la parte general de la ciencia social, que trata de determinar el carácter de las fuerzas que actúan en evolución y las formas de coordinación que sê establecen dentro de una sociedad, entre los diversos productos o círculos sociales. (22). En cambio el análisis particular de cada factor y producto sociales, constituye la materia de las ciencias particulares, conocidas como ciencias sociales. (23).

Siguiendo este esquema, Cornejo estudia, en la parte general de su sistema, contenida en el primer tomo de su obra, los productos primarios; no como tales propiamente dichos, sino como factores o fuerzas. En cambio en el segundo tomo, o parte especial, los trata desde el punto de vista de la descriptiva de cada uno de ellos. Prácticamente esta división de factores y productos sólo se reduce a un buen propósito, pues tanto unos como otros no contienen sin la exposición de la teoría de Wundt sobre el lenguaje, mito, religión, arte, costumbres, derecho y moral.

(22) Cornejo, Sociología, etc., p. 102.

(23) Ibid., p. 102. 
También en su segundo tomo agrega estudios sobre el matrimonio, la familia, el Estado y la ciencia, desde el punto de vista descriptivo.

El primer proceso general voluntario es, para Cornejo, la imitación, tomada íntegramente de la obra de Tarde.

Gabrie Tarde publicó su obra fundamental, en materia social, "Les lois de l'imitatión", en 1890-95 afliándose a la escuela psicologista y pretendiendo explicar la totalidad del proceso sccial por medio de la imitación o repetición de la conducta.

Afirma Tarde que todos los nuevos rasgos culturales dimanan de individuos creadores que son imitados por la multitud o el grupo, siendo por ello necesario, para que surjan nuevas especies de conducta social, que se monifiesten los procesos innovadores del individuo, e imitativo de la sociedad.

Consecuentemente, también el hombre creador es cualitativamente äiferente de la multitud de imitadores, $y$ el procedimiento de la invención es el secreto del genio.

Considerando la asociación como actividades intermentales de un grupo de personas, cree el profesor francés que ellas se derivan de tres procesos fundamentales : imitación, oposición y adaptación.

Con referencia al primero, asegura que la fuente de la acción social debe encontrarse en las iniciativas individuales, o invenciones que dan lugar al acto socializador de la imitación, por el cual aquellas llegon a ser socialmente aceptados por los demósas

De la misma manera, la imitación debe sujetarse a diferentes leyes y factores. En primer lugar, toda imitación tiencle a propagarse en progresión geométrica, por lo que respecta al número de personas afectadas. Asimismo, es interferida por los factores físicos y biológicos, incluyendo las características raciales, o sea que son refractadas por su medio. Por otra parte, sufren influencias sociales que pueden ser lógicas y extralógicas. Las causas lógicas operan siempre que un individuo prefiera una imitación a otra, porque piense que es más útil - más verdadera que las demás; esto es, más de acuerdo con las asplraciones y principios que ya han encontrado puesto en su mente. Las causas extralógicas interfieren las limitaciones haciendo que los movimientos internos se imiten antes que los externos, es decir las ideas son transmitidas antes que los medios, sin la conciencia de la conveniencia para las anteriores imitaciones ya asimiladas. 'Consecuencia de esta ley, es que las imitaciones por causa extralógica marchen de los socialmente superiores a los inferiores, y que se alternen épocas de costumbres en las cuales el pasado tiene un prestigio peculiar, con épocas 
de moda dominadas por el prestigio de la novedad y de lo extranjero.

En cuanto al proceso de oposición, afirma Tarde debe buscársele en el seno del individuo, ahí donde titubee entre adoptar o rechazar un nuevo ejemplo que se le ofrece. Los tres tipos principales de oposición son : la guerra, la competencia y la polémica.

Por fin, del tercer proceso, o sea la adaptación, se encuentra en el cerebro y espíritu individual del inventor, pues una armonía entre las ideas de los individuos es esencial para la armonía de los espíritus de los diferentes miembros de una sociedad.

Estos tres términos - concluye Tarde- constituyen una serie circular capaz de avanzar incesantemente. Por medio de la repetición imitativa es como Ia invención, adaptación social fundamental, se extiende $\mathrm{y}$ fortalece, suscitando polémicas o produciendo nuevas y más complejas invenciones, que dan lugar a otras imitaciones, y así indefinitivamente. Las correlaciones de los tres términos -repetición, oposición y adaptación- son fácilmente comprendidas cuando consideramos repeticiones sucesivas actuando, unas veces en favor de la adaptación, y otras de la oposición. (24).

Cornejo sin embargo, ha interpolado en la teoría de Tarde, conceptos importantes que lo reafirman dentro de la escuela positiva $y$ evolucionista.

Hábilmente concilia la idea del ritmo de Spencer, con la repetición de Tarde. La imitación, dice, es el ritmo que la vida colectiva impone a los movimientos de expresión, creando un nuevo género de semejanzas sociales. A las repeticiones nacidas de la unidad de los procesos fisiológico y psicológicor se agreganelas que derivan de la sugestión recíproca que, entre sí, ejercen los miembros de una sociedad. (25).

$\mathrm{Su}$ formación espenceriana se manifiesta una vez más, porque no cree que la imitación, considerada como base de lá vida social, presuponga la idea que la sociedad sea la creación y la obra, no de fuerzas naturales, sino fruto de algunos centenares de hombres superiores que han inventado todos los productos sociales.

Si alguna verdad ha demostrado el estudio de la historia - afirmaes que la época hace al hombre y no el hombre a la época. (26).

Igualmente, interpola en la teoría original de Tarde, las ideas de la evolución a las que se había adherido fervientemente al comienzo de su obra. Habiendo considerado con Spencer que en la evolución

(24) Tarde, Les lois de l'imitation, 1890.

(25) Cornejo, Sociología, etc., p. 418.

(26) Ibid., p. 420. 
hay dos procesos : de diferenciación y de asimilación, conviene que éste último ln constituye, en la sociedad, los procesos de imitación y educación. La imitación es la manera como asimila la sociedad los productos individuales; y la educación la forma como el individuo asimila los productos sociales. (27).

Nuevamente es necesario repetir, la importancia de Cornejo reside en la adeucada forma como reelabora dentro de la filosofía positiva y teoría de la evolución, los principios generales enunciados por multitud de investigadores sociales, uno de cuyos mejores ejemplos lo encontramos, sin duda alguna, en el sentido con que trata la teoría de la imitación de Gabriel Tarde.

Sin embargo, Cornejo, no acepta en su totalidad las ideas del pensador francés, a quien hace muy graves e importantes objeciones.

En primer lugar, guíado por su formación positiva y espenceriana. rechaza la idea que la imitación sea la causa universal y única de los fenómenos sociales, como lo propugnaba Tarde, Hay pensamientos y formas comunes a toda especie, independientes de la imitación, que no se derivan de un mismo modelo, sino son efecto del número ilimitado de ideas que circulan por el alma de los pueblos. Bastian ha sido, en ésto, su principal inspirador (28).

En segundo lugar, es opuesto a las ideas de Tarde en cuanto a la luchas de las inveciones, porque, asegura, aparte de los elementos psíquicos hay factores físicos y biológicos que contribuyen a la organización y funcionamiento de Iac sociedad. Síguiendo la misma doctrina, afirma que los duelos entre las anitguas $y$ nuevas invenciones no explican ni comprenden esas luchas por los intereses cuyos origenes estan en los instintos de conservación y reproducción y en los sentimientos que de ellos se derivan, luchas que no parten de ninguna invención, aunque sean éstas las que cambien sus formas. (29).

Por último, también critica al pensador francés su aseveración qus la imitación extralógica se produzca de los individuos o clases inferiores a los superiores. Es evidente que el superior es frecuentemente imitado, pero también existe la imitación del superior al inferior. debido no a la admiración sino a la influencia del medio que es incesante. produciéndose, en este caso, acciones de la colectividad sobre el individuo. (30).

(27) Ibid., p. 423.
(28) Ibid., p. 419.
(29) Ibid., p. 431.
(30) Ibid., p. 434.


En resumen, las objeciones hechas por Cornejo a Tarde son vá. lidas en cuanto afirman que la imitación no es suficiente para explicar la totalidad de las acciones e instituciones sociales.

El segundo factor de la homogeneidad social es la educación, tomada como el proceso mediante el cual la colectividad trasmite al individuo sus modos de pensar, sentir y obrar. Es indudable, en este aspecto, la poderosa influencia de Durkheim en la estructuración de los conceptos mencionados por Cornejo.

Considerando que la educación abraza todos los órdenes de la actividad colectiva, enlaza nuevamente sus ideas sobre los factores sociales con el principio de la evolución, que informa todo su sistema. La educación consiste en la continuación del proceso biológico (31).

La educación, continúa, no puede trasmitir al individuo sino las ideas de que está en posesión el grupo social, y de ahí la limitación de su poder de transformación, que explicaría la estabilidad de muchas colectividades en que la educación es esmerada, como China, límites que se borran paulatinamente mediante el aumento de las comunicaciones entre los pueblos.

Luego Cornejo aborda la necesidad de sistematizar la educación eligiendo los conocimientos que convengan generalizar, y determinando los métodos que deben emplearse para su trasmisión. Solamente el Esstado podría universalizar la educación y convertirla en el principal agente de la igualdad.

Nada de esta última parte, sin embargo, se refiere a los temas propios de la Sociología, puesto que ella tiene un campo especial de investigación, sin necesifar incursiondir dentró deola problemática de otras disciplinas pedagógicas. La metodología de la educación y la política educacional correcta pertenecen a la filosofía de aquella, pero no $\alpha$ la Sociología, que solamente está autorizada a estudiar los hechos tal como se presentan en la sociedad.

Terminando el estudio de los procesos de homogenización social, Cornejo ingresa al examen de la heterogeneidad de la sociedad y los grupos. Los factores determinantes, según su opinión, serían la división del trabajo y la guerra.

Al hablar del primer factor, divulga las ideas expuestas por Durkheim en su conocida obra "De la división du travail social", y las cumplementa con algunas tomadas del economista inglés Adam Smith.

Desde el origen de las comunidades, afirma, puede reconocerse dos formas de división del trabajo: la autoritaria y la voluntaria. El

(31) Ibid., p. 441. 
primer proceso tiene como agente la fuerza, ya empleada directamente, ya representada por la autoridad que coordina los esfuerzos separados; mientras el segundio nace de la necesidad de aprovecharse de las cosas, dóndoles el dominador común del valor, que permite sean cambicdas una por otros. (32).

Entre las causas de la división del trabajo, señala Cornejo la fundamental excrinada por Durkhein : la clensidad material y moral de la población: y añade dos causas concurrentes: las desigualdades físicas del medio $y$ biológicas de la raza e individuos, y los progresos de la técnica y desenvolvimiento de la organizacion.

Durkheim afirma que la división del trabajo varia según el valumen y la densidacl de una sociedad. Sin embargo, el problema de la aivisión del trabajo debe ser estudiajo, en Durkheim, juntamente con los vínculos que unen la sociedad, y ésta, ha expresado el sociólogo francés, no es une mera pluralidad de individuos ni una yuxtaposición mecánica de seres humanos, sino una organización, un sistema de relaciones más o menos definido y más o Irsnos permanente.

El vínculo social por excelencia es la solidaridad. El derecho penal -afirma- nos revela un tipo de solidaridad o cohesión social que deriva del hecho de catraerse los individuos reciprocamente porque se consideran semejantes $o$, mejor dicho, poseen un fondo de creencias y prácticas comunes a todos ellos. A esfo llama solidaridad mecánica. (33). En cambio en el derecho restitutivo, la solidaridad que corresponde es de naturclezo completomente distinta, pues los sentimientos despertados por la violagión de esas reglas no son lo suficientemente violentos ni severes como para exigir la aplicación de un castigo. L1 derecho restitutivo es una manifestación del tipo de solidaridad que se funda en la existencia de diferencias recíprocas y complementarias y, consecuentemente, en la división del trabajo. Esta solidaridad la denomina orgúnica.

Sin embargo, la principal objeción que se ha hecho a Durkheım, con referencia a su teoria sobre las causas de la división del trabajo, es que un hecho demográfico -el aumento de la densidad de la población- es biológico y no social en el sentido cultural en que debe tomarse el término.

Comejo, al incorporar la teoría de Durkheim a su sistema de Sociología y dentro de los factores sociales, ha tomado en cuentex el aspecto diferenciador del proceso, adecućndolo, de acuerdo con su orien-

(32) Ibid, p. 454

(33) Durkheim, De la àivisión, etc, p. 155. 
tación general, a la evolución de las formas de la sociedad, y señalcmdo como efectos del fenómeno, en primer lugar, la división de la comunidad en grupos que se diferencion por la manera de ejercer su actividad, que organizados constituyen las corporaciones; y en segundo lugar, la formación de las clases, cuando a raíz de la división del trabajo se reúnen consecuencias derivadas de la diferenciación autoritaria. como la adquisición desigual de la propiedad y el reconocimiento de sus privilegios, que se traduciría por una posición jerárquica indepencliente del valor de las funciones que los individuos desempeñan, apareciendo las castas cuando las closes se vinculan a la herencia. (34).

El último factor que favorece la evolución, segin el sistema de Comejo, es la guerra. Pora desarrollar el tema, el sociólogo aprovecha Ios estudios de la escuela darwinista que hiza de la lucha el principal incentivo de todo el desenvolvimiento colectivo, $y$ afirma que dentro de la synergia social ese principio contribuye a la organización de los grupos humanos, y corresponde, por su naturaleza, al proceso de difcrenciación.

L,os motivos que delerminan las guerras, tanto internas como externas, esto es dentro del grupo y entre grupos vecinos, serín económicos, religiosos, de rivalidad y gloria, pero sobre todo, to que Nietzche ha llamado "voluntad de poder".

El proceso de infegración gue la guerra se manifiesta en la organizcición del les grupos, aumentando la masa. Mediante la conquista, alima, los grupos simples se asimilan a otres unidgdes, formándose los compuestos. Pero éste crecimiento tendría un término, derivado de las posibilidades de "quilibrio, por el que sellega a" cierto estado social en que la diferenciación de los grupos es tal que no es posible la asimilación de la conquista.

Cornejo vincula también la guerra con su idea central de la solidaridad, haciendo ver que pare contribuir a la organización del grupo, supone que éste se encuentre fuertemente vinculado, es decir requiere de la existencia de la solidaridad o sea de la unidad moral del grupo.

Otro punto importante en su estudio de la guerra, es la asimilación de las ideas de Spencer sobre el trónsito del militarismo al industrialismo, afirmación que fundabr, el sociólogo inglés, en la presunción que la evolución lleva al hombre a un estado de perfecta adaptación, mediante la reducción contínua de conflictos piimarios, a un imperio cada vez mayor de la razón y de la toleranciar, resumen de los

(34) Cornejo, Sociología, etc., p. 461. 
anhelos humanos apoyados en la voluntad popular antes que en la presión de la fuerza. En lo que no concuerda Cornejo, es en la desaparición del tipo guerrero, ya que el Estado perdería la casi totalidad de sus atribuciones, que el industrialismo, lejos de disminuír, habría multiplicado.

Termina así Mariano H. Cornejo con la exposición de su sistema, que no es sino la ordenación y clasificación de una serie de escuelas de Sociología, complementadas con la inclusión del principio de la solidaridad, como fundamento y resultado último de la acción de las diversas fuerzas que deberían actuar dentro de los grupos naturales.

En este sentido, el sistema sociológico de Cornejo representa la tendencia sintética en el estudio de los problemas sociales. Su obra significó un esfuerzo por sistematizar, en un todo orgónico, la casi totalidad de la elaboración conceptual que hasta entonces se habia producido.
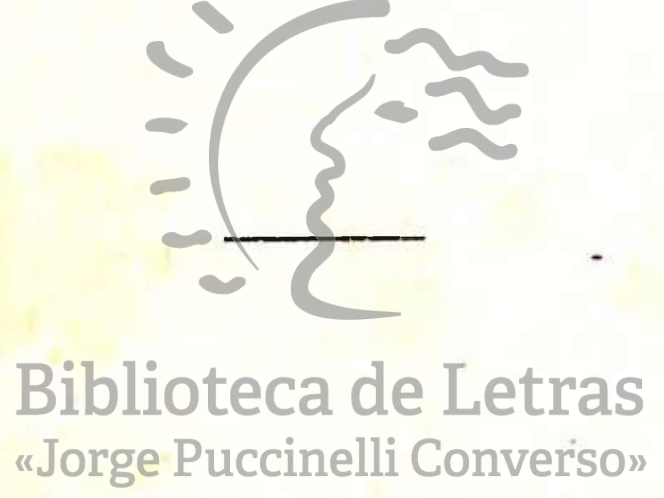